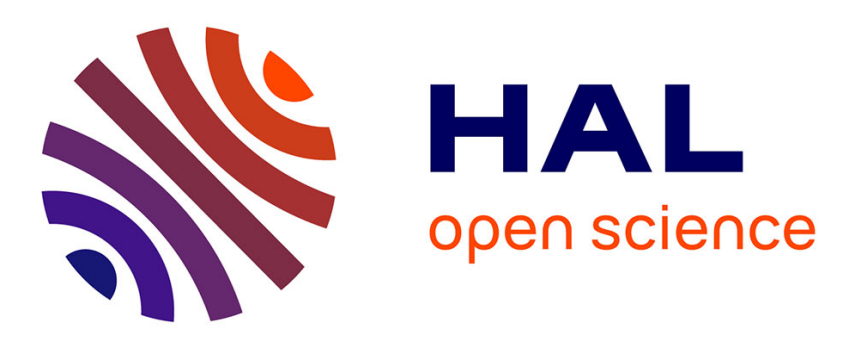

\title{
Macrophage functionality and homeostasis in response to oligoethyleneglycol-coated IONPs: Impact of a dendritic architecture
}

\author{
Anne Casset, Julien Jouhannaud, Antonio Garofalo, Coralie Spiegelhalter, \\ Dinh-Vu Nguyen, Delphine Felder-Flesch, Geneviève Pourroy, Françoise Pons
}

\section{To cite this version:}

Anne Casset, Julien Jouhannaud, Antonio Garofalo, Coralie Spiegelhalter, Dinh-Vu Nguyen, et al.. Macrophage functionality and homeostasis in response to oligoethyleneglycol-coated IONPs: Impact of a dendritic architecture. International Journal of Pharmaceutics, 2019, 556, pp.287-300. 10.1016/j.ijpharm.2018.12.024 . hal-02129899

\section{HAL Id: hal-02129899 \\ https://hal.science/hal-02129899}

Submitted on 23 Oct 2020

HAL is a multi-disciplinary open access archive for the deposit and dissemination of scientific research documents, whether they are published or not. The documents may come from teaching and research institutions in France or abroad, or from public or private research centers.
L'archive ouverte pluridisciplinaire HAL, est destinée au dépôt et à la diffusion de documents scientifiques de niveau recherche, publiés ou non, émanant des établissements d'enseignement et de recherche français ou étrangers, des laboratoires publics ou privés. 
Macrophage functionality and homeostasis in response to oligoethyleneglycol-coated IONPs: impact of a dendritic architecture.

Anne CASSET ${ }^{a}$, Julien JOUHANNAUD, Antonio GAROFALO ${ }^{b}$, Coralie SPIEGELHALTER ${ }^{c}$, Dinh-Vu NGUYEN ${ }^{b}$, Delphine FELDER-FLESCH ${ }^{b}$, Geneviève POURROY ${ }^{b}$, Françoise PONS.

“Université de Strasbourg, CNRS, CAMB UMR 7199, F-67000 Strasbourg, France

- Université de Strasbourg, CNRS, Institut de Physique et Chimie des Matériaux Strasbourg, UMR 7504, F-67000 Strasbourg, France.

c Institut de Génétique et de Biologie Moléculaire et Cellulaire (IGBMC), INSERM, CNRS, Université de Strasbourg, F-67404 Illkirch, France.

Corresponding author.

E-mail address: casset@unistra.fr 


\begin{abstract}
The engineering of iron oxide nanoparticles (IONPs) for biomedical use has received great interest over the past decade. In the present study we investigated the biocompatibility of IONPs grafted with linear (2P) or generation 1 (2PG1) or 2 (2PG2) dendronized oligoethyleneglycol units in THP-1-derived macrophages. To evaluate IONP effects on cell functionality and homeostasis, mitochondrial function (MTT assay), membrane permeability (LDH release), inflammation (IL-8), oxidative stress (reduced glutathione, GSH), NLRP3inflammasome activation (IL-1 $\beta$ ) and nanoparticle cellular uptake (intracellular iron content) were quantified after a 4 -h or $24-\mathrm{h}$ cell exposure to increasing IONP concentrations $(0-300 \mu \mathrm{g}$ Fe/mL). IONPs coated with a linear molecule, NP10COP@2P, were highly taken up by cells and induced significant dose-dependent IL-8 release, oxidative stress and NLRP3 inflammasome activation. In comparison, IONPs coated with dendrons of generation 1 (NP10COP@2PG1) and 2 (NP10COP@2PG2) exhibited better biocompatibility. Effect of the dendritic architecture of the surface coating was investigated in a kinetic experiment involving cell short-term exposure (30 $\mathrm{min}$ or $1 \mathrm{~h} 30)$ to the two dendronized IONPs. NP10COP@2PG2 disrupted cellular homeostasis (LDH release, IL-1 $\beta$ and IL-8 secretion) to a greater extend than NP10COP@2PG1, which makes this last IONP the best candidate as MRI contrast or theranostic agent.
\end{abstract}

Keywords:

Iron oxide, nanoparticles, dendron, oligoethyleneglycol, biocompatibility, MRI, theranostic. 


\section{Introduction}

The iron oxide nanoparticles (IONPs) exhibit useful properties such as magnetic behaviour and have been developed for various applications in technology and medicine (Hola et al., 2015). The engineering of IONPs generates promising platforms in nanomedicine and in particular in magnetic hyperthermia, drug delivery, MRI-assisted diagnosis or surgery (Houpeau et al., 2016; Kohler et al., 2005; Sonvico et al., 2005; Weissleder et al., 1990). Several IONP coatings, which present huge diversity in composition, were developed in order to improve the physicochemical properties of the nanoparticles (NPs) like their biocompatibility, stability and solubility in physiological conditions. Polymers such as dextran, chitosan, polyethylene glycol (PEG) or polyvinyl pyrrolidone (PVP) were the most frequently used so far (Mahmoudi et al., 2010). A dendritic coating strategy for the design of functional IONPs presents a special interest when small-sized and well-defined dendrons are grafted on the surface of IONPs. Surface coating of NPs with PEG chains has been described to improve their dispersity and stability, to reduce protein adsorption on their surface and therefore to increase the NP blood half time by reducing their rapid clearance by the reticuloendothelial system (RES) (Gref et al., 2000; Sun et al., 2010; Walkey et al., 2012).

Different strategies have been previously explored to develop dendronized IONP-based contrast agents. NPs were synthesized by coprecipitation leading to naked $\mathrm{Fe}_{3} \mathrm{O}_{4} \mathrm{NPs}$ in water and different grafting strategies have been used involving mono-phosphonic acids to provide stable anchoring at the metal oxide surfaces through P-O metal iono-covalent bonds, while preserving the intrinsic properties of the IONPs (Daou et al., 2009; Lamanna et al., 2011). Then, a stronger anchoring of the dendron on the IONP surface via biphosphonate tweezers has been described leading to good colloidal stability in water and in isoosmolar media (Basly et al., 2010; Basly et al., 2013). Indeed, it has been highlighted that dendronized IONPs stay stable for a long time in physiological media (Walter et al., 2015), are eliminated by urinary and hepatobiliary pathways within a few hours post-intravenous injection (Basly et al., 2011; Lamanna et al., 2011), are escaping the RES (Walter et al., 2014), and induce a very high MRI contrast enhancement even if hydrophobic specific targeting ligands are grafted on their periphery (Bordeianu et al., 2018). Those previous results led collectively to the synthesis and characterization of three different dendronized IONPs. The dendrons are based on oligoethyleneglycol units, one hexa or octaethyleneglycol chain ended with a carboxylate function, adjoined or not to two tetraethyleneglycol chains. One of the IONP coating is linear (labeled 2P) and the two others are dendritic and of generation 1 and 2 (labeled 2PG1 and 2PG2, respectively).

IONPs have been used in biomedical applications, in particular as MRI contrast agents with commercially available preparations approved by the FDA for clinical use as early as the 
1990s (Benetti et al., 2014; Novotna et al., 2012). Currently, ferumoxytol, a polyglucose sorbitol carboxymethylether, is the only IONP available in clinics. It is indicated for the treatment of iron deficiency anemia in adult patients with chronic kidney disease or with intolerance or unsatisfactory response to oral iron. It is well tolerated. Risks of hypersensitivity including anaphylaxic shock have been reported although they are rare (Akhuemonkhan et al., 2018; Auerbach et al., 2018). This warrants the search for alternative IONPs for other biomedical applications involving investigations on the undesirable effects associated with IONPs (Soenen et al., 2015). Historically, the IONPs were considered as safe, based on studies revealing no noticeable cytotoxity of bare NPs when it became evident that the specific properties of these NPs modify their toxic potential (Jeng and Swanson, 2006; Lee et al., 2007). First, toxicological effects of IONPs have been shown to be dose (Naqvi et al., 2010; Sadeghi et al., 2015), size (Karlsson et al., 2009; Ying and Hwang, 2010) and surface coating dependent (Ali et al., 2015; Friedrich et al., 2015; Sharma et al., 2014). Then, the iron redox state has been shown to influence the cellular toxicity and the DNA damage ability of the NPs as highlighted with dextran-coated IONPs of identical core size and surface chemistry (Singh et al., 2012). Finally, a cell-specific cytotoxicity has been reported (Ali et al., 2015; Ding et al., 2010). Overall, the current literature indicates the importance of addressing IONP cytotoxicity in an integrated approach, including characterization of the NPs together with evaluation of their cell internalization and their effects on cellular functions for an adequate evaluation of their biocompatibility.

Macrophages are tissue-resident phagocytic cells and constitute an important part of the mononuclear phagocyte system (MPS). They take a central part in iron homeostasis as well. After entering the body, NPs are rapidly cleared by macrophages and other cells of the MPS. Their NPs avid uptake might make macrophages more susceptible to particle overload, iron dys-homeostasis and cell death (Benetti et al., 2014; Hoppstadter et al., 2015; Napierska et al., 2010). Therefore, assessment of IONP uptake by macrophages and their cytotoxicity towards these phagocytic cells is particularly relevant. Thus, previous studies indicated that bare IONPs could promote a pro-inflammatory phenotype in macrophages (Kodali et al., 2013; Laskar et al., 2013).

In the present study, we evaluated the effects of IONPs grafted with linear (2P) or generation 1 (2PG1) or 2 (2PG2) dendronized oligoethyleneglycol units on functionality and homeostasis of THP-1-derived macrophages. The cell viability was investigated by assessing the mitochondrial function (MTT assay) and the membrane permeability (LDH release) of cells incubated for 4 and 24 hours with the different decorated IONPs. Those parameters were measured at the end of the incubation period, as well as after a recovery period. Cellular internalization of the IONPs was evidenced by transmission electron microscopy (TEM) and quantified by measuring intracellular iron levels. Cell oxidative stress status and activation of 
the nucleotide-binding oligomerization domain (NOD)-like receptor containing pyrin domain 3 (NLRP3) inflammasome were determined in order to assess the IONP effects on cell homeostasis. The specific physicochemical properties of the IONPs are presented with emphasis on their cellular uptake and compatibility.

\section{Material and methods}

\subsection{IONP synthesis and characterization}

\subsubsection{Synthesis of IONPS}

The chemical reagents used in this work were iron chloride hexahydrate $\left(\mathrm{FeCl}_{3}, 6 \mathrm{H}_{2} \mathrm{O}, 99 \%\right.$ extra pure from Acros Organics), iron chloride tetrahydrate $\left(\mathrm{FeCl}_{2}, 4 \mathrm{H}_{2} \mathrm{O}\right.$, reagent plus $99 \%$ from Sigma-Aldrich), hydrochloric acid ( $\mathrm{HCl}$, min $37 \%$ from Sigma-Aldrich), and tetramethylammonium hydroxide $\left(\mathrm{N}_{(}\left(\mathrm{CH}_{3}\right)_{4} \mathrm{OH}, 25 \%\right.$ w/w aqua solution from AlfaAesar). The IONPs were prepared in water according to the method described previously (Salazar et al., 2011). The synthesis was carried out in a 3.751 Hastelloy ${ }^{\circledR}$ C276 (model 4553, Parr Instrument Inc.) autoclave. In a typical run, distilled water degassed with argon gas for half an hour was used. $150 \mathrm{ml}$ of $\mathrm{FeCl}_{3}, 6 \mathrm{H}_{2} \mathrm{O}(0.4 \mathrm{M})$ and $150 \mathrm{ml}$ of $\mathrm{FeCl}_{2}, 4 \mathrm{H}_{2} \mathrm{O}(0.2 \mathrm{M})$ were dissolved in $0.650 \mathrm{~L}$ of a $2 \mathrm{M} \mathrm{HCl}$ solution, and introduced in the autoclave under argon. The mixture was heated up to $40{ }^{\circ} \mathrm{C}$ under bubbling argon while being stirred with the mechanical stirrer. Then, 1.367 $\mathrm{L}$ of $1.37 \mathrm{M} \mathrm{N}\left(\mathrm{CH}_{3}\right)_{4} \mathrm{OH}$ solution was injected at $218.4 \mathrm{~mL} / \mathrm{min}$ and a vigorous stirring was carried on for $10 \mathrm{~min}$. During the experiment, argon was continuously passed through the solution to prevent the oxidation of the $\mathrm{Fe}^{2+}$ in the system. After $15 \mathrm{~min}$ of stirring at $40{ }^{\circ} \mathrm{C}$, the autoclave was slowly cooled down to room temperature. The IONPs were washed with deionized water by performing successively magnetic decantations and then centrifugations until the $\mathrm{pH}$ was neutral. The powder was attracted in the bottom of the vessel by a magnet (or by centrifugation) and the supernatant was removed and replaced by deionized water. The powder was then dispersed in an aqueous solution at $\mathrm{pH} 4.0$. These bare NPs were named NP10COP. Chemical analysis of the solution showed that the concentration is equal to $0.36 \mathrm{~g} / \mathrm{L}$.

\subsubsection{Synthesis of biocompatible phosphonic acids}

The structure of the three phosphonic acids (2P, 2PG1 and 2PG2) is characterized by: i) a phosphonic acid function that serves as an anchor point for grafting onto the surface of NPs, ii) a Gallate pattern that serves as a platform for diversifying the dendron functionality, iii) oligoethylene glycol chains that ensure good aqueous solubility of dendron and allow for further coupling of bioactive molecules (Fig. 1). The 2P molecule corresponds to 1-(3,5- 
bis(phosphonomethyl)phenoxy)-3,6,9,12-tetraoxapentadecan-15-oic acid, the 2PG1 molecule to 1-(2,6-bis((2,5,8,11-tetraoxatridecan-13-yl)oxy)-4-((2-(3,5-bis(phosphonomethyl)phenoxy) ethyl)carbamoyl)phenoxy)-3,6,9,12-tetraoxapentadecan-15-oic acid, and the 2PG2 molecule to $\quad 1,1^{\prime}-(((()((5-((2-(3,5-b i s($ phosphonomethyl)phenoxy)ethyl)carbamoyl)-1,3-phenylene) bis(oxy))bis(ethane-2,1-diyl))bis(azanediyl))bis(carbonyl))bis(2,6-bis((2,5,8,11tetraoxatridecan-13-yl)oxy)-4,1-phenylene))bis(oxy))bis(3,6,9,12-tetraoxapentadecan-15-oic acid). The three phosphonic acids were synthetized via a multistep sequence of classical organic chemistry reactions such as etherification, reduction, hydrogenolysis, Arbuzovreaction, as previously reported together with their full characterization (Garofalo et al., 2014). For example, the production of 2PG1 is achieved via a highly optimized 15-step protocol and was recently validated on a gram scale with an overall yield of $7 \%$ ( $>95 \%$ at each step).

\subsubsection{Preparation of the grafted IONPs}

The three molecules were grafted onto IONPs by mixing each of them and NPs in water. In the optimized process of functionalization, $20 \mathrm{~mL}$ of iron oxide suspension containing $7.2 \mathrm{mg}$ of $\mathrm{Fe}_{3} \mathrm{O}_{4}$ NPs were added to $2.2 \mathrm{mg}$ of dried phosphonic acid ( $\mathrm{pH}$ around 3). The functionalization step was optimized to obtain stable water suspensions of grafted IONPs. The direct grafting by introducing molecules in suspensions was demonstrated to occur at $\mathrm{pH} 4$ by interaction of negatively charged phosphonate groups with hydroxyl and positively charged groups at the iron oxide surface (Daou et al., 2009). Then, $\mathrm{NaOH}$ was added in order to reach a $\mathrm{pH}$ value of 4.0 depending on the molecule nature as discussed previously (Basly et al., 2010). The suspension was sonicated in a standard laboratory sonicator (Transsonic 275/H Prolabo) for $10 \mathrm{~min}$ and the solution was mixed for $10 \mathrm{~min}$ by rocking/rolling action (Digital Tube Roller SRT9D/Stuart). Then $\mathrm{NaOH}$ was added in order to reach a $\mathrm{pH}$ value of 6.0 and the solution was mixed for one day at least by rocking/rolling action. The grafted NPs were separated from the ungrafted molecules by ultrafiltration. This technique uses regenerated cellulose membranes with a nominal molecular weight limit (NMWL) of $3 \mathrm{kDa}$ purchased from Ultracel®. The water suspension was introduced in the apparatus and ultrafiltration (purification) occurred by pressurizing the solution flow. The solvent and ungrafted molecules went through the membrane while the grafted NPs did not. They were then redispersed in 20 $\mathrm{mL}$ of water and submitted to another ultrafiltration step. This was done five times. After such purification step, the $\mathrm{pH}$ value of the NP suspension was around 7.4. The obtained 
suspensions were labeled NP10COP@2P, NP10COP@2PG1 and NP10COP@2PG2 owing to the molecule grafted on the IONPs.

\subsubsection{Characterization techniques}

The crystallographic structure of the IONPs was checked by powder X-ray diffraction (XRD) using a Bruker D8 Advance diffractometer equipped with a quartz monochromator, a Sol-X energy dispersive $\mathrm{X}$-ray detector and $\mathrm{Cu} \mathrm{K} \alpha$ radiation $(\lambda=0.154059 \mathrm{~nm})$. Profile matching refinements were performed through the Fullprof program (Rodriguez-Carvajal, 1993) using Le Bail's method with the modified Thompson-Cox-Hasting (TCH) pseudo-Voigt profile function (Thompson et al., 1987). TEM and HRTEM images of the bare IONPs in water suspension were recorded with a TOPCON model 002B transmission electron microscope, operating at $200 \mathrm{kV}$, with a point to point resolution of $0.18 \mathrm{~nm}$ to investigate the NPs morphology. The size of particles was measured on SEM and TEM images by analyzing 100 particles for each sample using the ImageJ software. IONP iron and phosphorus contents were determined by Inductively Coupled Plasma/Atomic Emission Spectroscopy (ICP-AES). To do so, $2 \mathrm{~mL}$ of concentrated $\mathrm{HCl}$ were added to $750 \mu \mathrm{L}$ of NP suspensions. The samples were then submitted to ultrasounds to get a complete NP dissolution. Before analysis using a Varian VISTA MPX ICP spectrometer, sample volume was adjusted to $25 \mathrm{~mL}$ with distilled water. Infrared spectra of the bare and grafted NPs were recorded from 4000 to $400 \mathrm{~cm}^{-1}$ with a Fourier Transform Infrared (FTIR) spectrometer (DIGILAB FTS 3000 Excalibur series). Samples were gently ground and diluted in nonabsorbent $\mathrm{KBr}$ matrixes. The size distribution and zeta potential of the bare and dendronized-IONPs were measured in water at $\mathrm{pH} 4.0$ or 7.4 using a Nano ZS zetasizer (Malvern).

\subsection{Biological evaluation of the IONPs}

\subsubsection{Cell culture}

Immortalized human monocytes (THP-1, ATCC) were grown in culture flasks (Falcon) containing RPMI 1640 culture medium supplemented with L-glutamine $(2 \mathrm{mM})$, heatinactivated fetal bovine serum $(10 \%, \mathrm{v} / \mathrm{v})$, penicillin $(100 \mathrm{U} / \mathrm{mL})$, streptomycin $(100 \mu \mathrm{g} / \mathrm{mL})$, and 2-mercaptoethanol $(0.05 \mathrm{mM})$. Culture medium and all reagents, excepted 2mercaptomethanol (Serva Electrophoresis $\mathrm{GmbH}$ ) were manufactured by Gibco and obtained from Invitrogen, France. Cells were maintained at $37^{\circ} \mathrm{C}$ in a $5 \% \mathrm{CO}_{2}$ atmosphere. When the culture reached $0.8-1.0 \times 10^{\circ}$ cells $/ \mathrm{mL}$, cells were centrifuged $\left(120 \mathrm{~g}, 5 \mathrm{~min}, 4^{\circ} \mathrm{C}\right)$ and resuspended in culture medium at a $2.5 \times 10^{s}$ cells $/ \mathrm{mL}$ density to establish subculture or were seeded in culture plates for experimentation.

\subsubsection{Cell exposure to dendronized iron oxide nanoparticles}


Cells were seeded at a density of $0.5 \times 10^{5}$ and $1.2 \times 10^{4}$ cells/well on $24-$ and $96-w e l l$ plates (Falcon), respectively, and treated with $10 \mathrm{ng} / \mathrm{mL}$ phorbol 12-myristate 13-acetate (PMA, Sigma-Aldrich) for $24 \mathrm{~h}$ to induce monocyte differentiation into macrophages, which was confirmed by cell becoming adherent (Aldo et al., 2013). After culture medium removal, cells were washed with phosphate buffered saline (PBS) and exposed to IONPs suspended in culture medium for $4 \mathrm{~h}$ or $24 \mathrm{~h}$. Stock solutions of IONPs were sonicated in a bath (Bioblock Scientific, Strasbourg, France) at a frequency of $40 \mathrm{kHz}$ for $20 \mathrm{~min}$ before their dilution in culture medium. Concentrations of interest in IONPs $(3.125,6.25,12.5,25,50,100,200$ and $300 \mu \mathrm{g} \mathrm{Fe} / \mathrm{mL}$ ) were obtained by diluting the stock solutions into culture medium. IONP preparations were sonicated $(40 \mathrm{kHz}, 4 \mathrm{~min})$ just before their application on THP-1 cells. Control cells without treatment were included in all experiments. Cells exposed to $100 \mu \mathrm{M}$ $\mathrm{H}_{2} \mathrm{O}_{2}$ or $0.1 \mu \mathrm{g} / \mathrm{mLlipopolysaccharides} \mathrm{(LPS,} \mathrm{E.} \mathrm{coli} \mathrm{055:B5,} \mathrm{Sigma} \mathrm{Aldrich)} \mathrm{were} \mathrm{included} \mathrm{as}$ positive control, when assessing oxidative stress and inflammasome activation, respectively.

\subsubsection{Cell cytotoxicity assessment}

Cell cytotoxicity was assessed by measuring mitochondrial function and cell membrane integrity. Mitochondrial function was measured by determining the capacity of mitochondria to reduce the tetrazolium salt 3-(4,5-dimethylthiazol)-2,5-diphenyltetrazolium bromide (MTT) into formazan. After exposure to IONPs or exposure to IONPs followed by a recovery period, the cells were washed with PBS and MTT $(1 \mathrm{mg} / \mathrm{mL}$ culture medium) was added. After a 1-hour incubation at $37^{\circ} \mathrm{C}$, the dye solution was removed and formazan crystals were dissolved by inducing cell lysis with dimethyl sulfoxide. Absorbance of the resulting solution was read at $570 \mathrm{~nm}$ using a Multiskan FC reader (Thermo Scientific). Mitochondrial function was expressed as the percentage of the absorbance of treated cells relative to the absorbance of non-exposed cells. Cell membrane integrity was assessed by measuring the release in the culture medium of the cytosolic enzyme lactate deshydrogenase (LDH). This assay was performed with the Cytotoxicity Detection Kit Plus (Roche Applied Science) according to the manufacturer's instructions. Data were expressed as percentage of LDH release by calculating the percentage of the absorbance of treated cells relative to the absorbance of non-exposed cells treated with the kit lysis solution.

\subsubsection{Intracellular iron quantification}

Intracellular iron content was measured as previously described by Zhu et al. with slight modifications (Zhu et al., 2012). Briefly, cells were seeded on 24-well culture plates, activated with PMA and exposed to IONPs, as described above. After a 4-h exposure to IONPs, cells were washed once with PBS, released with trypsin-EDTA and counted. Cells were then collected by centrifugation at 4,500 $\mathrm{g}$ for $5 \mathrm{~min}$, resuspended in a $12 \% \mathrm{HCl}$ solution and incubated at $60^{\circ} \mathrm{C}$ (dry bath, Fischer Scientific) for $4 \mathrm{~h}$. After the incubation, the samples were centrifuged at $12,000 \mathrm{~g}$ for $10 \mathrm{~min}$, and the resulting supernatants were collected for iron 
quantification. For iron assay, an iron calibration curve (Fe concentration from 0.25 to 10 $\mathrm{mg} / \mathrm{L}$ ) was freshly prepared in $12 \% \mathrm{HCl}$ from a $\mathrm{FeCl}_{2}, 4 \mathrm{H}_{2} \mathrm{O}$ stock solution (Merck). Samples, standards or blank $(12 \% \mathrm{HCl})$ were transferred into the wells of a microtitration plate, before addition of $1 \%$ ammonium persulfate (Sigma Aldrich) and $0.1 \mathrm{M}$ potassium thiocyanate (Sigma Aldrich). The microtitration plate was incubated for $10 \mathrm{~min}$ at room temperature to form the iron-thiocyanate complex. Absorbance of the complex was measured at $490 \mathrm{~nm}$ using a Multiskan FC reader (Thermo Scientific). The value obtained for the blank was subtracted from standard and sample values. Fe concentration in samples was determined from the calibration curve and expressed as $\mu \mathrm{g} / \mathrm{cell}$. The detection limit of the assay method was $0.05 \mu \mathrm{g} / \mathrm{mL}$. The method was validated by assaying the iron concentration in the IONP suspensions prepared in culture medium for the cell exposure. IONP suspensions at a concentration of $100 \mu \mathrm{g} \mathrm{Fe} / \mathrm{mL}$ were assayed with a CV of $7.8 \%(\mathrm{n}=10)$.

\subsubsection{Transmission electron microscopy on cells exposed to IONPS}

Cells were seeded on 7.8 mils thick Aclar® films placed in 24-well culture plate as previously described (Laverny et al., 2013). After activation with PMA for $24 \mathrm{~h}$, the culture medium was removed, and the cells were washed once with PBS and exposed to IONPs as described above. After a 4-h exposure, cells were washed once with PBS and fixed with $2.5 \%$ glutaraldehyde and $2.5 \%$ formaldehyde in $0.1 \mathrm{M}$ cacodylate buffer. Cells were then post-fixed with $1 \%$ osmium tetroxide, and en-bloc stained with $2 \%$ uranyl acetate. The samples were then dehydrated in graded ethanol solutions $(25 \%, 50 \%, 70 \%, 90 \%, 3 \times 100 \%)$ and embedded in Epon resin. After resin polymerization at $60^{\circ} \mathrm{C}$, ultrathin sections $(60 \mathrm{~nm})$ were collected on grids and post-stained or not with uranyl acetate $(10 \mathrm{~min})$ and lead citrate $(5 \mathrm{~min})$. Grids were then examined at $80 \mathrm{kV}$ under a Philips CM12 electron microscope equipped with a Gatan Orius 1000 CCD camera.

\subsubsection{Quantification of intracellular reduced glutathione}

The oxidative stress status of the cells was evaluated by the quantification of the intracellular reduced glutathione (GSH) using the method described by Lewicki (Lewicki et al., 2006). Cells were seeded on 96-well culture plate, activated with PMA and exposed to IONPs as described above. Cells treated with $100 \mathrm{mM} \mathrm{H}_{2} \mathrm{O}_{2}$ for $4 \mathrm{~h}$ were included in the experiment as positive control. After a 4-h exposure, cells were washed once with a washing solution $(5 \mathrm{mM}$ EDTA, $40 \mathrm{mM} \mathrm{NaH} \mathrm{PO}_{4}, 100 \mathrm{mM} \mathrm{Na}_{2} \mathrm{HPO}_{4}, \mathrm{pH}$ 7.4) and treated with a lysis solution $(0.1 \%$ Triton-X100 in washing buffer) for $15 \mathrm{~min}$ at room temperature. Twenty $\mu \mathrm{L}$ of cellular lysate were transferred in a 96-well microtitration plate for protein assay using the BCA method (reagents from Sigma-Aldrich) and bovine serum albumin as standard for calibration curve. The remaining cellular lysate were acidified with $0.1 \mathrm{M} \mathrm{HCl}$. After protein precipitation with a $50 \%$ sulfosalicylic acid solution, lysates were centrifuged at $10,000 \mathrm{~g}$ and $4^{\circ} \mathrm{C}$ for $15 \mathrm{~min}$, and stored at $-80^{\circ} \mathrm{C}$ until GSH assay. For GSH assay, the samples were defrosted and diluted 
10 -fold in the lysis solution. A calibration curve of GSH (0.06 to $16 \mu \mathrm{M})$ was freshly prepared in the lysis solution from a $4 \mathrm{mM}$ stock solution prepared in PBS (Sigma Aldrich). Sixty $\mu \mathrm{L}$ of cell extract samples, GSH standards or lysis solution (blank) were transferred into wells of a 96-well microtitration plate before addition of borate buffer ( $0.2 \mathrm{M}$ boric acid, 0.05 $\mathrm{mM}$ sodium tetraborate, $\mathrm{pH} 9.0)$ and naphthalene-2,3-dicarboxaldehyde $(1 \mathrm{mg} / \mathrm{mL}$ in ethanol; Sigma-Aldrich). The plate was incubated for $25 \mathrm{~min}$ at $4^{\circ} \mathrm{C}$ in darkness. The fluorescence intensity was immediately measured using a Varioskan ${ }^{\circledR}$ Flash microplate reader (Thermo Fischer Scientific, Vantaa, Finland) with an excitation filter set at $485 \mathrm{~nm}$ and an emission filter set at $528 \mathrm{~nm}$. The value of the blank was subtracted from standard and sample values. GSH levels in samples were determined from the calibration curve and expressed as $\mathrm{mg} / \mathrm{g}$ proteins.

\subsubsection{Cytokine assays}

IL-8 (eBioscience), IL-6 (eBioscience) and IL-1 $\beta$ (R\&D Systems ${ }^{\mathrm{TM}}$ ) were measured in cell supernatants by ELISA according to manufacturer's instructions.

\subsection{Statistics}

Results were expressed as arithmetic means \pm standard error of the mean (SEM). Statistical analysis were performed using Prism software (version 5; GraphPad Software Inc, La Jolla, CA). If not otherwise stated, statistical significance was determined by tow-way ANOVA followed by Dunnett's multiple comparison test. In order to compare the intracellular iron concentrations, one-way ANOVA followed by Tukey's multiple comparison test was applied. Two-way ANOVA followed by Bonferroni's multiple comparison test was performed in the kinetic experiment. Data were considered as statistically different when $p<0.05$.

\section{Results}

\subsection{Characterization of nanoparticles and of suspensions}

The bare NPs, NP10COP were fully characterized after drying the water suspension according to previous publications (Salazar et al., 2011). The X-ray diffraction pattern exhibits the diffraction lines of the spinel structure (Fig. S1, see supplementary information). The refinement leads to a lattice parameter equal to $\mathrm{a}=0.8367(1)$, intermediate between magnetite ( $\mathrm{a}=0.8392 \mathrm{~nm}$ JCPDS No. 19-0629) and maghemite ones (0.8346 nm, JCPDS file $39-1346)$ and a particle size of $8( \pm 1) \mathrm{nm}$. The NP morphology and size were observed by TEM (Fig. 2). The size calculated on images by using the ImageJ software is equal to 8.8 $(0.5) \mathrm{nm}$ (Fig. 2C), which is in agreement with X-ray diffraction analysis. FTIR spectra were recorded for NP10COP@2P, NP10COP@2PG1 and NP10COP@2PG2 suspensions and compared to the molecule (2P, 2PG1 and 2PG2) and the bare IONP (NP10COP) spectra (Fig. 
S2, see supplementary information). The spectra of dendron molecules are similar to the spectra already published (Walter et al., 2015). The characteristic bands of methylene group vibrations are at $2920 \mathrm{~cm}^{-1}\left(\nu_{\mathrm{as}} \mathrm{C}-\mathrm{H}\right)$ and $2850 \mathrm{~cm}^{-1}\left(\nu_{\mathrm{s}} \mathrm{C}-\mathrm{H}\right)$, a carbonyl vibration of the carboxylic acid function is observed at $1734 \mathrm{~cm}^{-1}$. The numerous bands between 1690 and $1320 \mathrm{~cm}^{-1}$ are attributed to N-H, N-C and C-NO bonds and those between 1375 and $1200 \mathrm{~cm}$ $\mathrm{cm}^{-1}$ are associated with the $\mathrm{C}-\mathrm{H}$ bonds from the oligo(ethyleneglycol) (OEG) chains. The bands at $1100 \mathrm{~cm}^{-1}$ are associated to the $\mathrm{C}-\mathrm{O}-\mathrm{C}$ bonds of $\mathrm{OEG}$ chains, whereas the band at $1180 \mathrm{~cm}^{-1}$ is attributed to the $\mathrm{P}=\mathrm{O}$ bond and those at 1032 and $995 \mathrm{~cm}^{-1}$ to $\mathrm{P}-\mathrm{OH}$ bonds. The spectrum recorded on bare NPs exhibits only a wide band in the 500-800 cm range occurring from Fe-O bonds of the oxide structure. This band is visible on the spectra recorded for NP10COP@2P, NP10COP@2PG1 and NP10COP@2PG2. The characteristic bands of methylene group vibrations at $2800-3000 \mathrm{~cm}$ become more intense when 2PG2 is involved compared to $2 \mathrm{P}$ and $2 \mathrm{PG} 1$. A band characteristic of water appears in the $1550-1700 \mathrm{~cm}^{-1}$ range. The intensity of the $\mathrm{P}=\mathrm{O}$ bands decrease and bands attributed to Fe-O-P vibrations appear showing that the dendrons have been grafted on the IONPs. DLS analysis of the bare IONPs in water suspension ( $\mathrm{pH} 4$ ) indicates a particle size of $95 \pm 5 \mathrm{~nm}$ and a charge (zeta potential) of $+39 \pm 2 \mathrm{mV}$ (Table 1). Particles in grafted IONP water suspensions (pH7) exhibit negative charge in agreement with previous works (Basly et al., 2010). The size of particles in NP10COP@2PG1 and NP10COP@2PG2 suspensions are reduced with respect to the bare IONP ones, whereas NP10COP@2P particles has higher hydrodynamic diameter (Table 1). Dynamic magnetic measurements of the suspensions also support these observations (see Supplementary Information, Figure S3). The concentration of iron and the grafting ratio were determined by chemical analysis (ICP-AES). The composition of the suspensions in terms of iron and phosphorus is given in Table 2, as well as the iron to molecule ratio. The grafting ratio, i.e. the number of molecules per surface area calculated assuming that the NPs are spherical with a diameter equal to $8.8 \mathrm{~nm}$, decreases from 2P to 2PG1 and to 2PG2. Indeed, the larger the molecule the lower the number of molecules grafted on the NPs.

From $T_{1}$ and $T_{2}$ values measured as a function of concentration by relaxometry at $1.5 \mathrm{~T}$ and $37^{\circ} \mathrm{C}$, relaxivity values as high as $259 \mathrm{mM}^{-1} \mathrm{~s}^{-1}$ and $249 \mathrm{mM}^{-1} \mathrm{~S}^{-1}$ for $\mathrm{r}_{2}$ and $16 \mathrm{mM}^{-1} \mathrm{~S}^{-1}$ for $\mathrm{r}_{1}$, with a $16 r_{2} / r_{1}$ ratio, were obtained for NP10COP@2PG1 and NP10COP@2PG2, respectively (see Supplementary Information, Table S1 and Fig. S4.). One has to notice that NP10COP@2P also showed similar values $\left(263 \mathrm{mM}^{-1} \mathrm{~S}^{-1}\right.$ for $\mathrm{r}_{2}$ and $15 \mathrm{mM}^{-1} \mathrm{~s}^{-1}$ for $\mathrm{r}_{1}$, with a $15 \mathrm{r}_{2} / \mathrm{r}_{1}$ ratio $)$ but those results must be put in parallel with the fact that those NPs exhibit a much higher hydrodynamic size $(140 \pm 10 \mathrm{~nm})$ than the two dendronized NPs $(72 \pm 5 \mathrm{~nm}$ for NP10COP@2PG1 and $74 \pm 5$ nm for NP10COP@2PG2) (Table 1).

\subsection{Dose-dependent cytotoxic effects of IONPs}


To investigate the cytotoxic effects of IONPs on THP-1-derived macrophages, the cells were exposed to increasing concentrations of NP10COP@2P, NP10COP@2PG1 or NP10COP@2PG2 (from 3.125 to $300 \mu \mathrm{g} \mathrm{Fe} / \mathrm{mL}$ ) for $24 \mathrm{~h}$. At the endpoint $24 \mathrm{~h}$, cell viability was investigated by measuring the mitochondrial activity and the LDH release, as an index of membrane integrity. The mitochondrial function was assessed by a MTT assay, which has been widely used to investigate the cytotoxicity of IONPs in vitro (Jie et al., 2012; Scialla et al., 2017; Zhu et al., 2012). The results are shown in Fig. 3. NP10COP@2P did affect the mitochondrial function of the cells in a dose-dependent manner (Fig. 3A). Indeed, at the lower concentrations (3.125 to $25 \mu \mathrm{g} \mathrm{Fe} / \mathrm{mL}$ ), NP10COP@2P induced a significant increase in mitochondrial function, suggesting cell activation. Such an effect has been previously observed in various studies with bare $\mathrm{Fe}_{3} \mathrm{O}_{4}$ NPs $\left(\mathrm{D}_{\mathrm{c}}=30\right.$ and $\left.47 \mathrm{~nm}\right)$ or silica-coated IONPs $\left(D_{c}=27\right.$ and $48.8 \mathrm{~nm} ; D_{\mathrm{r}}=44.4$ and $\left.125.6 \mathrm{~nm}\right)$, as well as with NPs of other composition such as silver NPs (Hussain et al., 2005; Kunzmann et al., 2011; Sarkar et al., 2015). However, at the highest concentration of $300 \mu \mathrm{g}$ Fe/mL, NP10COP@2P triggered a 65\% decrease in THP1 mitochondrial activity reaching statistical significance. On the contrary, NP10COP@2PG1 and NP10COP@2PG2 did not affect the mitochondrial function of THP-1-derived macrophages including at the highest concentration of $300 \mu \mathrm{g} \mathrm{Fe} / \mathrm{mL}$.

Regarding membrane integrity, exposure of THP-1-derived macrophages to IONPs for $24 \mathrm{~h}$ resulted in a dose-dependent effect for the 3 NPs (Fig. 3B). NP10COP@2P evoked the highest LDH leakages reaching 14, 28 and 45\% when cells were exposed to 100, 200 and 300 $\mu \mathrm{g}$ Fe/mL, respectively. Comparatively, NP10COP@2PG1 and NP10COP@2PG2 induced less toxic effect, since LDH leakages induced by these NPs at the same concentrations reached $8 \%, 15 \%$ and $28 \%$, and $11 \%, 22 \%$ and $36 \%$, respectively. Altogether, the results underlined a stronger effect of NP10COP@2P, both on the mitochondrial function and the membrane integrity. Importantly, no cytotoxic effect was observed after a 24-h cell exposure to the three coating molecules (2P, 2PG1 or 2PG2) alone (see supplementary information, Fig. S5).

\subsection{Effects of a post-exposure recovery period on cytotoxicity and inflammation}

To evaluate a possible recovery of THP-1-derived macrophages from acute cytotoxicity of IONPs, cells were exposed for $4 \mathrm{~h}$ to increasing concentrations (3.125 to $300 \mu \mathrm{g} \mathrm{Fe} / \mathrm{mL}$ ) of NP10COP@2P, NP10COP@2PG1 or NP10COP@2PG2, and cytotoxicity was measured at the end of the exposure period $(4 \mathrm{~h})$ or after a 20 -h recovery period $(24 \mathrm{~h})$. As shown in Fig. $4 \mathrm{~A}$, at the end of the 4-h exposure period, NP10COP@2P induced a significant decrease in cell mitochondrial function of 33,58 and $87 \%$ at the concentrations of 100, 200 and $300 \mu \mathrm{g}$ $\mathrm{Fe} / \mathrm{mL}$, respectively. In contrast, NP10COP@2PG1 and NP10COP@2PG2 exhibited no effect. However, the three IONPs induced a dose-dependent loss in membrane integrity (Fig. 4B). A $58 \% \mathrm{LDH}$ release was indeed observed at the concentration of $300 \mu \mathrm{g} \mathrm{Fe} / \mathrm{mL}$ for NP10COP@2P, while NP10COP@2PG1 and NP10COP@2PG2 induced respectively, 25 and 
$33 \%$ of enzyme release at the same concentration. After the 20 -h recovery period, cells exposed for $4 \mathrm{~h}$ to 100 and $200 \mu \mathrm{g}$ Fe/mL of NP10COP@2P had recovered their full mitochondrial activity, although those exposed to $300 \mu \mathrm{g} / \mathrm{mL}$ NP10COP@2P still exhibited a significant decrease in their activity (Fig. 4C). Exposure to NP10COP@2PG1 and NP10COP@2PG2 still resulted in any decrease in cell mitochondrial function whatever the concentrations (Fig. 4C). Furthermore, the three IONPs triggered no significant LDH leakage including at the highest dose of $300 \mu \mathrm{g} / \mathrm{mL}$. Although little or no change in cell viability was observed in cells exposed to IONPs for 4-h and cultured an additional 20h-duration to allow recovery, a dose-dependent increase in IL- 8 and IL- 6 release was observed in these exposure conditions for the three IONPs (Fig. 4E and 4F). However, once again, a stronger effect was obtained in cells exposed to NP10COP@2P. Indeed, significant IL-8 concentrations of 57.2, 108.9 , and $121.9 \mathrm{ng} / \mathrm{mL}$ were measured in the culture supernatant of cells exposed to 100,200 and $300 \mu \mathrm{g} / \mathrm{mL}$ of $\mathrm{NP10COP} @ 2 \mathrm{P}$, respectively. NP10COP@2PG2 at those high concentrations did trigger significant IL-8 release as well, whereas the IL-8 release evoked by NP10COP@2PG1 reached significance at 200 and $300 \mu \mathrm{g} \mathrm{Fe} / \mathrm{mL}$ (Fig. 4E). A similar dosedependent effect of the three IONPs was also observed for IL-6 secretion (Fig. 4F). Interestingly, increases in IL-6 release in response to NP10COP@2PG1 were non significant.

\subsection{Effects of IONPs on the intracellular GSH levels}

Oxidative stress in response to IONPs has been reported in the literature (Diaz et al., 2008; Mahmoudi et al., 2012). Oxidative stress causes lipid peroxidation that disrupt the phospholipid-bilayer membrane and can result in loss in membrane integrity. Reduced glutathione (GSH) is a major cellular anti-oxidant. Its decrease in living systems is a hallmark of oxidative stress (Hussain et al., 2005; Pongrac et al., 2016). After a 4-h exposure to increasing concentrations of NP10COP@2P, NP10COP@2PG1 or NP10COP@2PG2 (from 3.125 to $300 \mu \mathrm{g} \mathrm{Fe} / \mathrm{mL}$ ), cellular levels of GSH were measured using the method based on the reaction between GSH and the naphthalene-2,3-dicarboxaldehyde probe (NDA). Exposure to NP10COP@2P generated oxidative stress in THP-1-derived macrophages as reflected by reduced GSH levels (Fig. 5). This effect was concentration-dependent and significant at the highest IONP concentrations (200 and $300 \mu \mathrm{g} \mathrm{Fe} / \mathrm{mL}$ ). The decrease in GSH level observed at the concentration of $300 \mu \mathrm{g} \mathrm{Fe} / \mathrm{mL}$ was similar in intensity to the one induced by $100 \mathrm{mM}$ $\mathrm{H}_{2} \mathrm{O}_{2}$ (positive control). Interestingly, NP10COP@2PG1 and NP10COP@2PG2 did not affect the GSH levels whatever their concentration. Therefore, only the NP10COP@2P IONPs seemed to induce oxidative stress.

\subsection{Effects of IONPs on the NLRP3 inflammasome}

Oxidative stress, among other mechanisms, may led to activation of the NLRP3 inflammasome, which plays a critical role in innate immunity by triggering the release of the 
pro-inflammatory cytokine interleukin-1 $\beta$ (IL-1 $\beta$ ) (Sutterwala et al., 2014). Thus, we investigated IL-1 $\beta$ release by THP-1-derived macrophages in response to exposure to increasing concentrations (3.125 to $300 \mu \mathrm{g}$ Fe/mL) of NP10COP@2P, NP10COP@2PG1 or NP10COP@2PG2 for $4 \mathrm{~h}$. IL-1 $\beta$ concentrations were measured at the end of exposure in the cell culture supernatant by ELISA. An increasing dose-dependent IL-1 $\beta$ release was observed for the three IONPs (Fig. 6). At all concentrations tested, NP10COP@2P induced a higher IL$1 \beta$ release compared to NP10COP@2PG1 and NP10COP@2PG2. Thus, the increase in IL-1 $\beta$ release evoked by NP10COP@2P was significant from $25 \mu \mathrm{g} \mathrm{Fe} / \mathrm{mL}$, in contrast to NP10COP@2PG1 and NP10COP@2PG2. Furthermore, at this concentration, the IL-1 $\beta$ release induced by the particle was 4.3 and 4.9 -fold greater that the one provoked by NP10COP@2PG1 and NP10COP@2PG2, respectively.

\subsection{Cellular uptake of the IONPs}

The IONP internalization was evaluated by the quantification of the intracellular iron content and by cell imaging by TEM. THP-1-derived macrophages were exposed to $100 \mu \mathrm{g} \mathrm{Fe} / \mathrm{mL}$ NP10COP@2P, NP10COP@2PG1 or NP10COP@2PG2 for $4 \mathrm{~h}$. This concentration was chosen as it is the lowest that induces a significant biological response at this time point (Fig. 4). Indeed, a significant loss in cell viability was observed after a 4-h exposure to NP10COP@2P, when NP10COP@2PG1 and NP10COP@2PG2 showed no significant cytotoxic effects. We hypothesized that this difference of toxicity was due to a difference in the internalization rate of NP10COP@2P compared to NP10COP@2PG1 and NP10COP@2PG2. Intracellular iron quantification was performed by a colorimetric method (Fig. 7). As iron is an essential microelement that is necessary for physiological functions of the human body, a basal iron concentration of $0.24 \pm 0.03 \mathrm{pg} / \mathrm{cell}$ was found in untreated cells. This level is comparable to concentrations previously reported in THP-1 cells (Janic et al., 2009; Ludwig et al., 2013; Raynal et al., 2004). Cells exposed to NP10COP@2P, NP10COP@2PG1 and NP10COP@2PG2 exhibited a 37.1, 5.9 and 14.3-fold increase in intracellular iron content compared to the non-exposed cells, respectively. Thus, the NP10COP@2P-treated cells showed the highest iron content with a concentration of $8.99 \pm$ $1.4 \mathrm{pg} \mathrm{Fe} / \mathrm{cell}$.

The TEM analysis of cells exposed to IONPs allowed us to visualize the internalization and localization of the particles (Fig. 8). Observations at a low magnification indicated an absence of important IONP aggregates (Fig. 8A), in contrast to previous observations reported in the literature (Jeon et al., 2016; Ludwig et al., 2013; Rojas et al., 2017). This confirmed the efficient dispersion of the IONPs in our biological preparations. The three nanoparticles appear internalized in vesicular structures in the cytoplasm (Fig. 8B and 8C). No IONP was observed free in the cytosol. NP10COP@2P was found in cluster of several NPs, in contrast 
to NP10COP@2PG1 and NP10COP@2PG2, which were found in endocellular vesicles as single events. Comparison of the repartition of the three IONPs in the cells confirmed that NP10COP@2P presented the highest cellular uptake at the time point of $4 \mathrm{~h}$ (Fig. 8D). High magnification observations (Fig. 8E) showed internalized NP with core size of $\approx 8-10 \mathrm{~nm}$, which is in agreement with the NP mean size $(8.8 \pm 0.5 \mathrm{~nm})$ measured on TEM images of NP10COP suspensions (Fig. 2C).

\subsection{IONP surface coating effects on cytotoxicity and inflammation}

In order to further investigate whether the dendritic architecture of the IONP surface coating modulates their cellular effects, we performed a kinetic experiment with NP10COP@2PG1 and NP10COP@2PG2, characterized by the same size and a negative zeta potential, but different surface coatings (generation 1 and generation 2 dendrons, respectively). THP-1derived macrophages were exposed to increasing concentrations $(50,100$ and $200 \mu \mathrm{g} \mathrm{Fe} / \mathrm{mL})$ of NP10COP@2PG1 or NP10COP@2PG2 for 30 min or 1h30, followed or not by a recovery period in NP-free culture medium for up to $24 \mathrm{~h}$. At the endpoints $30 \mathrm{~min}$ and $1 \mathrm{~h} 30$, LDH release and IL-1ß secretion were assayed to assess membrane integrity and inflammasome activation, respectively. As shown in Fig. 9, NP10COP@2PG2 only evoked statistically significant LDH release. This effect was observed for the highest dose of NPs $(200 \mu \mathrm{g} / \mathrm{mL})$ after both $30 \mathrm{~min}$ - and $1 \mathrm{~h} 30$-exposures. The IL-1 $\beta$ release further underlined the specificity of the response induced by NP10COP@2PG2, as this NP induced a significantly higher IL-1 $\beta$ release after a $1 \mathrm{~h} 30$-exposure at the concentration of 100 and $200 \mu \mathrm{g} \mathrm{Fe} / \mathrm{mL}$ compared to NP10COP@2PG1. At the end of the recovery period in NP-free culture medium for up to $24 \mathrm{~h}$, IL-8 secretion was measured by ELISA. Some difference in IL-8 secretion was observed between the two NPs, as a 30-min exposure to $200 \mu \mathrm{g}$ Fe/mL NP10COP@2PG2 resulted in significantly higher IL-8 levels than exposure to the same concentration of NP10COP@2PG1. 


\section{Discussion}

This study aimed to evaluate the biocompatibility of three IONPs dysplaying a biphosphonate coating grafted with different oligoethyleneglycol-based dendrons on THP-1-derived macrophages. Our results showed that the IONPs coated with a linear molecule, namely NP10COP@2P, displayed cytotoxic effects upon short-term exposure, whereas the two other IONPs coated with generation 1 and 2 dendrons, namely NP10COP@2PG1 and NP10COP@2PG2, exhibited better biocompatibility. The toxic responses evoked by NP10COP@2P included release of the pro-inflammatory cytokine IL-8, oxidative stress and NLRP3 inflammasome activation, and were related to higher cellular uptake of the NPs. Therefore, these in vitro toxicological assessment seem to make the IONPs grafted with generation 1 (2PG1) or 2 (2PG2) dendronized oligoethyleneglycol units good candidates for preclinical in vivo ADME-T evaluations.

Historically, the IONPs were considered as safe, based on studies revealing no noticeable cytotoxic effects of bare NPs at concentrations up to $200 \mu \mathrm{g} / \mathrm{mL}$ (Jeng and Swanson, 2006; Lee et al., 2007). Hussain et al showed that $\mathrm{Fe}_{3} \mathrm{O}_{4}$ NPs had no measurable effect at low concentrations (10-50 $\mu \mathrm{g} / \mathrm{mL})$ while they triggered a significant effect at higher levels (100$250 \mu \mathrm{g} / \mathrm{mL}$ ) (Hussain et al., 2005). Gradually, it was established that bare IONPs could exhibit cytotoxic properties with a dose-response profile (Karlsson et al., 2009). For medical purposes, IONPs are often surface-coated to improve their hydrophilicity and conjugation capability. The materials used for these coatings are generally biocompatible. However, considering the cytotoxicity of the bare IONPs, it is of great importance to evaluate the role of the coating in limiting this cytotoxicity, without causing any other adverse effects. Due to the great diversity in surface coatings, a wide range of concentrations, from a few $\mu \mathrm{g} / \mathrm{mL}$ to 1 $\mathrm{mg} / \mathrm{mL}$, was tested and non-toxic concentrations were determined (Kunzmann et al., 2011; Muller et al., 2007; Soenen et al., 2010). These non-toxic concentrations appeared as coatingspecific, reaching $150 \mu \mathrm{g} \mathrm{Fe} / \mathrm{mL}$ for carboxydextran-coated IONPs (ferucarbotran), and 200 $\mu \mathrm{g} \mathrm{Fe} / \mathrm{mL}$ for citrate-coated IONPs (Very small Superparamagnetic iron Oxide Particles, VSOP C200) and dextran-coated IONPs (Endorem) (Gupta and Gupta, 2005; Soenen et al., 2011). Interestingly, ferucarbotran (Resovist ${ }^{\circledR}$ ), endorem and VSOP C184 have been clinically tested as MR contrast agents (ferucarbotran and endorem for MR imaging of the liver and VSOP C184 for MR angiography), with a favourable overall incidence of adverse events (Hundt et al., 2000; Reimer and Balzer, 2003; Wagner et al., 2011). Therefore, in the present study, we chose to assess the biological effects of our IONPs at concentrations ranging from 3.125 to $300 \mu \mathrm{g} \mathrm{Fe} / \mathrm{mL}$. 
We have first evaluated the cytotoxicity of IONPs using two different assays, e.g., MTT reduction and LDH release- The IONPs bearing a linear molecule (NP10COP@2P) induced cytotoxicity in a dose- and time-dependent manner. The mitochondrial metabolic activity of cells exposed to NP10COP@2P was significantly reduced after a 24-h exposure. Simultaneously, a dose-dependent loss in cell membrane integrity was observed. Similar results were found after a 4-h exposure to this IONP. On the contrary, the cell mitochondrial function was not affected by NP10COP@2PG1 or NP10COP@2PG2 bearing generation 1 and 2 dendrons respectively, even at high concentrations and after a 24-h exposure, although these IONPs triggered significant increases in LDH release at high concentrations. IONPs have been described to display various effects on cell viability, which seemed to depend at least partially on their cellular uptake efficiency. In our study, the highest intracellular iron concentration was observed after cell exposure to NP10COP@2P. Therefore, cytotoxicity was related to the IONP internalisation rate, in such a way that toxicity increased with uptake efficiency. Similar results have been previously reported with NPs composed of a multiparticle core of iron oxides, embedded in a PVP matrix and grafted with PEG acrylate. Those NPs were tested on cell lines of two different origins. The mesenchymal cells were found to be more sensitive to IONPs than the epithelial cells, which was related to their high capacity to internalize the IONPs (Ali et al., 2015). In keeping with our data, it has been previously reported that internalization of IONPs in endothelial cells was dependent on the nature of IONP coating (lauric acid, lauric acid/albumin or ferumoxytol) and resulted in a dose-dependent increase in toxicity related to high internalisation rate (Friedrich et al., 2015). Nevertheless, this relation between internalization rate and toxicity was not always observed. Experiments on endothelial cells using a transfection agent based on cationic units, Lipofectamine 2000, to increase internalization of the IONPs have shown a concentrationdependent uptake efficiency for the IONPs tested (Soenen et al., 2010). But, after a 24-h incubation at $1000 \mu \mathrm{g} \mathrm{Fe} / \mathrm{mL}$, citrate-coated IONPs induced a significant decrease in cell viability $(<80 \%)$, with an intracellular iron oxide concentration of $55.7 \mathrm{pg} \mathrm{Fe} / \mathrm{cell}$, whereas no toxic effect was noted for carboxydextran-coated IONPs despite an intracellular iron oxide concentration of $146.6 \mathrm{pg} \mathrm{Fe} / \mathrm{cell}$ (Soenen et al., 2010). Reports on the relation between the uptake efficiency and the cell viability have to be considered with caution since they refer to materials with different size, composition, surface charge, and structure, all of which have been shown to influence IONP cytotoxicity (Soenen et al., 2015).

The literature on IONP cellular uptake points to a size-dependent process. Studies on internalization of positively charged PVP-coated IONPs of different core sizes $\left(\mathrm{D}_{\mathrm{c}}=7.6,23.4\right.$, 36.8 and $65.3 \mathrm{~nm})$ and corresponding hydrodynamic diameters $\left(\mathrm{D}_{\mathrm{н}}=32.2,70.7,102.4\right.$, and $118.3 \mathrm{~nm}$ ) by mouse macrophages showed that the IONPs of $D_{c}=36.8 \mathrm{~nm}$ and $D_{\text {н }}=102.4 \mathrm{~nm}$ exhibited the highest uptake rate (Huang et al., 2010). Evaluation of the cellular uptake of dextran-coated IONPs in human T cells over a continuum of particle sizes of $D_{н}=33,53$ and 
$107 \mathrm{~nm}$ (with $\mathrm{D}_{\mathrm{c}}=6.1,5.6$ and $6.5 \mathrm{~nm}$, respectively), indicated that the highest internalization rate was observed for NPs of $D_{н}=107 \mathrm{~nm}$ (Thorek and Tsourkas, 2008). If some studies proposed an optimal hydrodynamic size for cell internalization around $100 \mathrm{~nm}$, results could differ depending on the coating material. In mice macrophages exposed to carboxydextrancoated IONPs with a $D_{\text {c }}$ of 4.5 to $5.4 \mathrm{~nm}$ and a $\mathrm{D}_{\text {н }}$ of 19 to $86 \mathrm{~nm}$, larger IONPs exhibited higher cell internalization, but uptake did no further increased when particle size exceeded 60 $\mathrm{nm}$ (Roohi et al., 2012). Our results showed a size-dependent uptake of the dendron-grafted IONPs in THP-1-derived macrophages. Indeed, NP10COP@2P $\left(D_{c}=8.8 \mathrm{~nm} ; D_{\mathrm{r}}=140 \mathrm{~nm}\right)$ exhibited the highest internalization rate compared to NP10COP@2PG1 or NP10COP@2PG2 $\left(D_{c}=8.8 \mathrm{~nm} ; \mathrm{D}_{\text {н }}=72\right.$ and $74 \mathrm{~nm}$, respectively) (Huang et al., 2010; Thorek and Tsourkas, 2008). NP10COP@2P differed from the two other IONPs by the size and its coating with a linear molecule composed of one hexaethyleneglycol chain ended with a carboxylate function. Previous observations in validation studies of the oligoethyleneglycol dendron concept revealed that the colloidal stability of such linear molecule was mainly due to electrostatic interactions in contrast to the generation 1 or 2 dendron, for which it is due to a combination of electrostatic and steric interactions (Walter et al., 2015). This linear molecule could therefore interact differently with the proteins present in the biological medium, which could be in favour of its cell internalisation. Furthermore, we observed that NP10COP@2PG2 internalization rate was twice as high as NP10COP@2PG1 uptake. If the two dendron-bearing IONPs presented the same hydrodynamic diameters, they differed by the dendritic architecture of their surface coating, which implied for the generation 2 dendron an increased number of branches, and therefore an increased number of carboxylate functions (103 versus 146 carboxylate functions per NP with generation 1 and 2, respectively). This could impact on the composition of the adsorbed proteins on their surface and consequently on their internalization rate as it was reported that coating polystyrene NPs with carboxylic functions induced a rapid binding of serum proteins to the NPs compared to the PEG-coated polystyrene NPs (Ehrenberg et al., 2009).

Previous studies showed that cells can take up IONPs in vitro via endocytosis and confine them into lysosomes where IONPs are degraded due to the lysosomal acidic $\mathrm{pH}$ and hydrolases (Wilhelm and Gazeau, 2008). We observed on TEM images, that after internalization NP10COP@2P, NP10COP@2PG1 and NP10COP@2PG2 were localized in defined vesicles, presumably structures of the endo-lysosomal pathway (Guarnieri et al., 2014). NP10COP@2P were found in clusters of several NPs in contrast to the other two IONPs, which were found as single events in vesicles. This difference of pattern could be related to different sensitivity of the NPs to $\mathrm{pH}$ change. Indeed, upon cell entry via endocytosis, the $\mathrm{pH}$ surrounding NP shifts from 7.4 in the extracellular medium to 6.0 in early endosomes and 4.5 in lysosomes. Thus, previous observations made on IONPs functionalized with a similar linear molecule as NP10COP@2P showed that these NPs were unstable and 
tend to form aggregates when placed at a $\mathrm{pH}$ below 6 . This could be attributed to the fact that the carboxylate end groups of the linear molecule are no more deprotonated at $\mathrm{pH} 6$, whereas in case of the generation 1 and generation 2 dendrons, the steric interactions induced by the dendron architecture maintain the stability of the NPs at acidic pH (Walter et al., 2015). Furthermore, accumulation of metallic NPs into endo-lysosomal compartments has been reported to be the main cause of toxicity due to their degradation and the in situ release of metal ions. Indeed, silica-coated IONPs delivered across the cell membrane directly into the cytosol using a pneumatic method, bypassing the formation of endocytic vesicles, induced no loss of cell viability after 1, 3 or 5 days of culture in contrast to endocytosed NPs (Guarnieri et al., 2014). The IONPs confined into lysosomal compartments undergo biodegradation and previous studies evidenced the role of the coating material in the kinetics of this degradation. The monitoring at the atomic scale of the biodegradation of nanocube IONPs in a medium mimicking intra-lysosomal environment suggested that polymer surface coatings control surface reactivity and prevent release of core materials that may cause toxicity to the biological systems with different degradation kinetics depending on the polymer coated (Lartigue et al., 2013). Therefore, in the present study, NP10COP@2P could undergo a rapid lysosomal degradation supporting their cytotoxic effects.

There is accumulating evidence that IONP toxicity encompasses the generation of oxidative stress resulting from the release of iron ions that catalyse the Fenton reaction. This reaction leads to the production of the hydroxyl radical, which is one of the most potent reactive oxygen species (Mesarosova et al., 2014; Pongrac et al., 2016; Sadeghi et al., 2015; Singh et al., 2012). Therefore, in our study, change in redox status of the cell was assessed by measuring intracellular reduced gluthatione $(\mathrm{GSH})$ as a major anti-oxydant. A significant reduction in GSH levels was observed with NP10COP@2P suggesting the implication of oxidative stress in the cytotoxicity induced by linear molecule-bearing IONPs. In contrast, NP10COP@2PG1 and NP10COP@2PG2 did not trigger significant changes in GSH levels, which is consistent with the lack of effects of these IONPs on THP-1 cell viability. These data suggest, that the dendritic oligoethyleneglycol coating material may prevent oxidative stress formation. In agreement with this hypothesis, it has been previously reported that bare $30 \mathrm{~nm}$ IONPs significantly increased ROS formation and cell death, while coating of the NPs with PEG results in reduced ROS formation and cell toxicity (Yu et al., 2012).

IL-8 is one of the numerous inflammatory cytokines and chemokines that are produced by macrophages and play a central role in the innate immune system response. It is produced in response to activation of $\mathrm{NF}-x \mathrm{~B}$, which is a redox-sensitive transcription factor controlling expression of gene encoding for inflammatory cytokines and chemokines. IL-8 production is therefore linked to oxidative stress. Interestingly, in the present study, all three IONPs 
induced significant IL-8 release, whereas NP10COP@2P only triggered oxidative stress. Previous studies reported that NF- $x$ B activation does not always occur in response to bare IONPs or dextran coated-IONPs (Murray et al., 2013). Thus, in our study, increase in IL-8 production induced by NP10COP@2P likely could result from activation of NF- $x \mathrm{~B}$ due to oxidative stress, whereas the one triggered by NP10COP@2PG1 and NP10COP@2PG2 may involve activation of another pathway.

Oxidative stress has been explored in many studies as a mechanism, among others, by which internalized particles lead to NLRP3 inflammasome activation (Cruz et al., 2007; Orlowski et al., 2015; Said-Sadier et al., 2010). Inflammasomes are assembled and activated in response to exogenous pathogens and endogenous danger signals, and are involved in the host defence and pathophysiology of several diseases. The NLRP3 inflammasome is a multiprotein complexes localized within the cytoplasm of the cell that is responsible for the maturation of pro-inflammatory cytokines such as interleukin-1 $\beta$ (IL-1 $\beta$ ) and IL-18. Many environmental or engineered particles of different sizes and shapes have been reported to activate the NLRP3 inflammasome (Dostert et al., 2008; Jessop et al., 2017; Simard et al., 2015) and particle internalisation has been shown as an essential step in this activation (Hornung et al., 2008) . But, IONPs have been reported to have contrasting effects on NLRP3 inflammasome. An increase in IL-1 $\beta$ concentration has been reported in vascular endothelial cells exposed to bare-magnetic ferroferric oxide NPs (Zhang et al., 2016). Similarly, PEG-coated IONPs induced the release of IL-1 $\beta$ in THP-1-derived macrophages. However, exposure of these cells to dextran-coated IONPs failed to trigger IL-1 $\beta$ release (Escamilla-Rivera et al., 2016). Furthermore, a decrease in IL-1 $\beta$ production has been observed in cells co-treated with oleic acid- or carboxydextran-coated IONPs and LPS (Grosse et al., 2016; Wu et al., 2013). Collectively, those results indicate that the nature of the NP coating has a major importance on NLRP3 inflammasome activation. In the present study, a 4-h exposure to NP10COP@2P induced a dose-dependent increase in IL-1 $\beta$ release. At all concentrations tested, NP10COP@2P induced a higher IL-1 $\beta$ release compared to NP10COP@2PG1 and NP10COP@2PG2, which is consistent with its capacity to induce oxidative stress. Nevertheless, at high concentrations (over $100 \mu \mathrm{g} / \mathrm{mL}$ ), NP10COP@2PG1 and NP10COP@2PG2 induced a significant increase in IL-1 $\beta$ release as well, although they did not seem to induce oxidative stress, which implies another pathway to activate the NLRP3 inflammasome and enhance the secretion of the pro-inflammatory cytokine IL-1 $\beta$. Multiple cellular signals have been proposed as inducers of NLRP3 inflammasome activation, including $\mathrm{K}^{+}$efflux, mitochondrial dysfunction, $\mathrm{Ca}^{2+}$ signaling or lysosomal leakage (He et al., 2016; Munoz-Planillo et al., 2013).

NP10COP@2PG1 and NP10COP@2PG2 presented the same hydrodynamic diameters $\left(\mathrm{D}_{\text {н }}=\right.$ $72 \pm 5$ and $74 \pm 5 \mathrm{~nm}$, respectively) and similar cytotoxic or pro-inflammatory effects, when 
evaluated after a 4-h or 24-h exposure. However, the two particles differed by the dendritic architecture of their surface coating. Therefore, in order to investigate whether this difference in architecture of surface coating modulates the cellular response triggered by the particles we performed a kinetic study at early time points. At the endpoint 1h30, NP10COP@2PG2 induced a significantly higher increase in LDH leakage and IL-1 $\beta$ release compared to NP10COP@2PG1. Those results indicated that the NP10COP@2PG2 could disrupt rapidly the cellular homeostasis compared to NP10COP@2PG1. Thus, taking collectively, our data on the three IONPs suggest that NP10COP@2PG1 would be the best candidate for MRI contrast agent.

In conclusion, we evaluated the effects on cell functionality and homeostasis of oligoethyleneglycol coated IONPs in THP-1-derived macrophage cells. NP10COP@2P coated with a linear molecule showed cytotoxicity related to its high internalization rate, and induced IL-8 release and NLRP3 inflammasome activation likely through induction of oxidative stress. In contrast, NP10COP@2PG1 and NP10COP@2PG2 showed good biocompatibility with low cytotoxicity and no oxidative response. At early time points, NP10COP@2PG2 disrupted more rapidly the cellular homeostasis than NP10COP@2PG1, which makes NP10COP@2PG1 the best candidate as MRI contrast or theranostic agent.

\section{Acknowledgements}

This research project was funded by CNRS, Unistra, and the European Regional Development Fund (ERDF) in the framework of the INTERREG V Upper Rhine program, "Transcending borders with every project", project NANOTRANSMED.

Declarations of interest: none. 


\section{References}

Akhuemonkhan, E., Parian, A., Carson, K.A., Hutfless, S., 2018. Adverse Reactions After Intravenous Iron Infusion Among Inflammatory Bowel Disease Patients in the United States, 2010-2014. Inflamm Bowel Dis 24, 1801-1807.

Aldo, P.B., Craveiro, V., Guller, S., Mor, G., 2013. Effect of Culture Conditions on the Phenotype of THP-1 Monocyte Cell Line. Am J Reprod Immunol 70, 80-86.

Ali, L.M.A., Pinol, R., Villa-Bellosta, R., Gabilondo, L., Milian, A., Palacio, F., Sorribas, V., 2015. Cell compatibility of a maghemite/polymer biomedical nanoplatform. Toxicol in Vitro 29, 962-975.

Auerbach, M., Chertow, G.M., Rosner, M., 2018. Ferumoxytol for the treatment of iron deficiency anemia. Expert Rev Hematol 11, 829-834.

Basly, B., Felder-Flesch, D., Perriat, P., Billotey, C., Taleb, J., Pourroy, G., Begin-Colin, S., 2010. Dendronized iron oxide nanoparticles as contrast agents for MRI. Chem Commun 46, 985-987.

Basly, B., Felder-Flesch, D., Perriat, P., Pourroy, G., Begin-Colin, S., 2011. Properties and suspension stability of dendronized iron oxide nanoparticles for MRI applications. Contrast Media Mol I 6, 132-138.

Basly, B., Popa, G., Fleutot, S., Pichon, B.P., Garofalo, A., Ghobril, C., Billotey, C., Berniard, A., Bonazza, P., Martinez, H., Felder-Flesch, D., Begin-Colin, S., 2013. Effect of the nanoparticle synthesis method on dendronized iron oxides as MRI contrast agents. Dalton T 42, 2146-2157.

Benetti, F., Bregoli, L., Olivato, I., Sabbioni, E., 2014. Effects of metal(loid)-based nanomaterials on essential element homeostasis: The central role of nanometallomics for nanotoxicology. Metallomics 6, 729-747.

Bordeianu, C., Parat, A., Piant, S., Walter, A., Zbaraszczuk-Affolter, C., Meyer, F., BeginColin, S., Boutry, S., Muller, R.N., Jouberton, E., Chezal, J.M., Labeille, B., Cinotti, E., Perrot, J.L., Miot-Noirault, E., Laurent, S., Felder-Flesch, D., 2018. Evaluation of the Active Targeting of Melanin Granules after Intravenous Injection of Dendronized Nanoparticles. Mol Pharmaceut 15, 536-547.

Cruz, C.M., Rinna, A., Forman, H.J., Ventura, A.L.M., Persechini, P.M., Ojcius, D.M., 2007. ATP activates a reactive oxygen species-dependent oxidative stress response and secretion of proinflammatory cytokines in macrophages. J Biol Chem 282, 2871-2879.

Daou, T.J., Pourroy, G., Greneche, J.M., Bertin, A., Felder-Flesch, D., Begin-Colin, S., 2009. Water soluble dendronized iron oxide nanoparticles. Dalton T, 4442-4449.

Diaz, B., Sanchez-Espinel, C., Arruebo, M., Faro, J., de Miguel, E., Magadan, S., Yague, C., Fernandez-Pacheco, R., Ibarra, M.R., Santamaria, J., Gonzalez-Fernandez, A., 2008. Assessing Methods for Blood Cell Cytotoxic Responses to Inorganic Nanoparticles and Nanoparticle Aggregates. Small 4, 2025-2034.

Ding, J., Tao, K., Li, J.Y., Song, S., Sun, K., 2010. Cell-specific cytotoxicity of dextranstabilized magnetite nanoparticles. Colloid Surface B 79, 184-190. 
Dostert, C., Petrilli, V., Van Bruggen, R., Steele, C., Mossman, B.T., Tschopp, J., 2008. Innate immune activation through Nalp3 inflammasome sensing of asbestos and silica. Science 320, 674-677.

Ehrenberg, M.S., Friedman, A.E., Finkelstein, J.N., Oberdorster, G., McGrath, J.L., 2009. The influence of protein adsorption on nanoparticle association with cultured endothelial cells. Biomaterials 30, 603-610.

Escamilla-Rivera, V., Uribe-Ramirez, M., Gonzalez-Pozos, S., Lozano, O., Lucas, S., De Vizcaya-Ruiz, A., 2016. Protein corona acts as a protective shield against Fe304-PEG inflammation and ROS-induced toxicity in human macrophages. Toxicol Lett 240, 172184.

Friedrich, R.P., Janko, C., Poettler, M., Tripal, P., Zaloga, J., Cicha, I., Durr, S., Nowak, J., Odenbach, S., Slabu, I., Liebl, M., Trahms, L., Stapf, M., Hilger, I., Lyer, S., Alexiou, C., 2015. Flow cytometry for intracellular SPION quantification: specificity and sensitivity in comparison with spectroscopic methods. Int J Nanomed 10, 4185-4201.

Garofalo, A., Parat, A., Bordeianu, C., Ghobril, C., Kueny-Stotz, M., Walter, A., Jouhannaud, J., Begin-Colin, S., Felder-Flesch, D., 2014. Efficient synthesis of small-sized phosphonated dendrons: potential organic coatings of iron oxide nanoparticles. New J Chem 38, 5226-5239.

Gref, R., Luck, M., Quellec, P., Marchand, M., Dellacherie, E., Harnisch, S., Blunk, T., Muller, R.H., 2000. 'Stealth' corona-core nanoparticles surface modified by polyethylene glycol (PEG): influences of the corona (PEG chain length and surface density) and of the core composition on phagocytic uptake and plasma protein adsorption. Colloid Surface B 18, 301-313.

Grosse, S., Stenvik, J., Nilsen, A.M., 2016. Iron oxide nanoparticles modulate lipopolysaccharide-induced inflammatory responses in primary human monocytes. Int J Nanomed 11, 4625-4642.

Guarnieri, D., Sabella, S., Muscetti, O., Belli, V., Malvindi, M.A., Fusco, S., De Luca, E., Pompa, P.P., Netti, P.A., 2014. Transport across the cell-membrane dictates nanoparticle fate and toxicity: a new paradigm in nanotoxicology. Nanoscale 6, 10264-10273.

Gupta, A.K., Gupta, M., 2005. Cytotoxicity suppression and cellular uptake enhancement of surface modified magnetic nanoparticles. Biomaterials 26, 1565-1573.

He, Y., Hara, H., Nunez, G., 2016. Mechanism and Regulation of NLRP3 Inflammasome Activation. Trends Biochem Sci 41, 1012-1021.

Hola, K., Markova, Z., Zoppellaro, G., Tucek, J., Zboril, R., 2015. Tailored functionalization of iron oxide nanoparticles for MRI, drug delivery, magnetic separation and immobilization of biosubstances. Biotechnol Adv 33, 1162-1176.

Hoppstadter, J., Seif, M., Dembek, A., Cavelius, C., Huwer, H., Kraegeloh, A., Kiemer, A.K., 2015. M2 polarization enhances silica nanoparticle uptake by macrophages. Front Pharmacol 6.

Hornung, V., Bauernfeind, F., Halle, A., Samstad, E.O., Kono, H., Rock, K.L., Fitzgerald, K.A., Latz, E., 2008. Silica crystals and aluminum salts activate the NALP3 inflammasome through phagosomal destabilization. Nat Immunol 9, 847-856.

Houpeau, J.L., Chauvet, M.P., Guillemin, F., Bendavid-Athias, C., Charitansky, H., Kramar, A., Giard, S., 2016. Sentinel Lymph Node Identification Using Superparamagnetic Iron 
Oxide Particles Versus Radioisotope: The French Sentimag Feasibility Trial. J Surg Oncol 113, 501-507.

Huang, J., Bu, L.H., Xie, J., Chen, K., Cheng, Z., Li, X.G., Chen, X.Y., 2010. Effects of Nanoparticle Size on Cellular Uptake and Liver MRI with Polyvinylpyrrolidone-Coated Iron Oxide Nanoparticles. Acs Nano 4, 7151-7160.

Hundt, W., Petsch, R., Helmberger, T., Reiser, M., 2000. Signal changes in liver and spleen after Endorem administration in patients with and without liver cirrhosis. Eur Radiol 10, 409-416.

Hussain, S.M., Hess, K.L., Gearhart, J.M., Geiss, K.T., Schlager, J.J., 2005. In vitro toxicity of nanoparticles in BRL 3A rat liver cells. Toxicol in Vitro 19, 975-983.

Janic, B., Rad, A.M., Jordan, E.K., Iskander, A.S.M., Ali, M.M., Varma, N.R.S., Frank, J.A., Arbab, A.S., 2009. Optimization and Validation of FePro Cell Labeling Method. Plos One 4.

Jeng, H.A., Swanson, J., 2006. Toxicity of metal oxide nanoparticles in mammalian cells. J Environ Sci Heal A 41, 2699-2711.

Jeon, S., Hurley, K.R., Bischof, J.C., Haynes, C.L., Hogan, C.J., 2016. Quantifying intra- and extracellular aggregation of iron oxide nanoparticles and its influence on specific absorption rate. Nanoscale 8, 16053-16064.

Jessop, F., Hamilton, R.F., Rhoderick, J.F., Fletcher, P., Holian, A., 2017. Phagolysosome acidification is required for silica and engineered nanoparticle-induced lysosome membrane permeabilization and resultant NLRP3 inflammasome activity. Toxicol Appl Pharm 318, 58-68.

Jie, L.Y., Cai, L.L., Wang, L.J., Ying, X.Y., Yu, R.S., Zhang, M.M., Du, Y.Z., 2012. Activelytargeted LTVSPWY peptide-modified magnetic nanoparticles for tumor imaging. Int J Nanomed 7, 3981-3989.

Karlsson, H.L., Gustafsson, J., Cronholm, P., Moller, L., 2009. Size-dependent toxicity of metal oxide particles-A comparison between nano- and micrometer size. Toxicol Lett $188,112-118$.

Kodali, V., Littke, M.H., Tilton, S.C., Teeguarden, J.G., Shi, L., Frevert, C.W., Wang, W., Pounds, J.G., Thrall, B.D., 2013. Dysregulation of Macrophage Activation Profiles by Engineered Nanoparticles. Acs Nano 7, 6997-7010.

Kohler, N., Sun, C., Wang, J., Zhang, M.Q., 2005. Methotrexate-modified superparamagnetic nanoparticles and their intracellular uptake into human cancer cells. Langmuir 21, 8858-8864.

Kunzmann, A., Andersson, B., Vogt, C., Feliu, N., Ye, F., Gabrielsson, S., Toprak, M.S., Buerki-Thurnherr, T., Laurent, S., Vahter, M., Krug, H., Muhammed, M., Scheynius, A., Fadeel, B., 2011. Efficient internalization of silica-coated iron oxide nanoparticles of different sizes by primary human macrophages and dendritic cells. Toxicol Appl Pharm 253, 81-93.

Lamanna, G., Kueny-Stotz, M., Mamlouk-Chaouachi, H., Ghobril, C., Basly, B., Bertin, A., Miladi, I., Billotey, C., Pourroy, G., Begin-Colin, S., Felder-Flesch, D., 2011. Dendronized iron oxide nanoparticles for multimodal imaging. Biomaterials 32, 8562-8573. 
Lartigue, L., Alloyeau, D., Kolosnjaj-Tabi, J., Javed, Y., Guardia, P., Riedinger, A., Pechoux, C., Pellegrino, T., Wilhelm, C., Gazeaut, F., 2013. Biodegradation of Iron Oxide Nanocubes: High-Resolution In Situ Monitoring. Acs Nano 7, 3939-3952.

Laskar, A., Eilertsen, J., Li, W., Yuan, X.M., 2013. SPION primes THP1 derived M2 macrophages towards M1-like macrophages. Biochem Bioph Res Co 441, 737-742.

Laverny, G., Casset, A., Purohit, A., Schaeffer, E., Spiegelhalter, C., de Blay, F., Pons, F., 2013. Immunomodulatory properties of multi-walled carbon nanotubes in peripheral blood mononuclear cells from healthy subjects and allergic patients. Toxicol Lett 217, 91-101.

Lee, J.H., Huh, Y.M., Jun, Y., Seo, J., Jang, J., Song, H.T., Kim, S., Cho, E.J., Yoon, H.G., Suh, J.S., Cheon, J., 2007. Artificially engineered magnetic nanoparticles for ultra-sensitive molecular imaging. Nat Med 13, 95-99.

Lewicki, K., Marchand, S., Matoub, L., Lulek, J., Coulon, J., Leroy, P., 2006. Development of a fluorescence-based microtiter plate method for the measurement of glutathione in yeast. Talanta 70, 876-882.

Ludwig, A., Poller, W.C., Westphal, K., Minkwitz, S., Lattig-Tunnemann, G., Metzkow, S., Stangl, K., Baumann, G., Taupitz, M., Wagner, S., Schnorr, J., Stangl, V., 2013. Rapid binding of electrostatically stabilized iron oxide nanoparticles to THP-1 monocytic cells via interaction with glycosaminoglycans. Basic Res Cardiol 108.

Mahmoudi, M., Hofmann, H., Rothen-Rutishauser, B., Petri-Fink, A., 2012. Assessing the In Vitro and In Vivo Toxicity of Superparamagnetic Iron Oxide Nanoparticles. Chem Rev 112, 2323-2338.

Mahmoudi, M., Milani, A.S., Stroeve, P., 2010. Synthesis, surface architecture and biological response of superparamagnatic iron oxide nanoparticles for application in drug delivery: a review. Int. J. of Biomedical Nanoscience and Nanotechnology 1, 164201.

Mesarosova, M., Kozics, K., Babelova, A., Regendova, E., Pastorek, M., Vnukova, D., Buliakova, B., Razga, F., Gabelova, A., 2014. The role of reactive oxygen species in the genotoxicity of surface-modified magnetite nanoparticles. Toxicol Lett 226, 303-313.

Muller, K., Skepper, J.N., Posfai, M., Trivedi, R., Howarth, S., Corot, C., Lancelot, E., Thompson, P.W., Brown, A.P., Gillard, J.H., 2007. Effect of ultrasmall superparamagnetic iron oxide nanoparticles (Ferumoxtran-10) on human monocyie-macrophages in vitro. Biomaterials 28, 1629-1642.

Munoz-Planillo, R., Kuffa, P., Martinez-Colon, G., Smith, B.L., Rajendiran, T.M., Nunez, G., 2013. K+ Efflux Is the Common Trigger of NLRP3 Inflammasome Activation by Bacterial Toxins and Particulate Matter. Immunity 38, 1142-1153.

Murray, A.R., Kisin, E., Inman, A., Young, S.H., Muhammed, M., Burks, T., Uheida, A., Tkach, A., Waltz, M., Castranova, V., Fadeel, B., Kagan, V.E., Riviere, J.E., Monteiro-Riviere, N., Shvedova, A.A., 2013. Oxidative Stress and Dermal Toxicity of Iron Oxide Nanoparticles In Vitro. Cell Biochem Biophys 67, 461-476.

Napierska, D., Thomassen, L.C.J., Lison, D., Martens, J.A., Hoet, P.H., 2010. The nanosilica hazard: another variable entity. Part Fibre Toxicol 7. 
Naqvi, S., Samim, M., Abdin, M.Z., Ahmed, F.J., Maitra, A.N., Prashant, C.K., Dinda, A.K., 2010. Concentration-dependent toxicity of iron oxide nanoparticles mediated by increased oxidative stress. Int J Nanomed 5, 983-989.

Novotna, B., Jendelova, P., Kapcalova, M., Rossner, P., Turnovcova, K., Bagryantseva, Y., Babic, M., Horak, D., Sykova, E., 2012. Oxidative damage to biological macromolecules in human bone marrow mesenchymal stromal cells labeled with various types of iron oxide nanoparticles. Toxicol Lett 210, 53-63.

Orlowski, G.M., Colbert, J.D., Sharma, S., Bogyo, M., Robertson, S.A., Rock, K.L., 2015. Multiple Cathepsins Promote Pro-IL-1 beta Synthesis and NLRP3-Mediated IL-1 beta Activation. J Immunol 195, 1685-1697.

Pongrac, I.M., Pavicic, I., Milic, M., Ahmed, L.B., Babic, M., Horak, D., Vrcek, I.V., Gajovic, S., 2016. Oxidative stress response in neural stem cells exposed to different superparamagnetic iron oxide nanoparticles. Int J Nanomed 11.

Raynal, I., Prigent, P., Peyramaure, S., Najid, A., Rebuzzi, C., Corot, C., 2004. Macrophage endocytosis of superparamagnetic iron oxide nanoparticles - Mechanisms and comparison of Ferumoxides and Ferumoxtran-10. Invest Radiol 39, 56-63.

Reimer, P., Balzer, T., 2003. Ferucarbotran (Resovist): a new clinically approved RESspecific contrast agent for contrast-enhanced MRI of the liver: properties, clinical development, and applications. Eur Radiol 13, 1266-1276.

Rodriguez-Carvajal, J., 1993. Recent advances in magnetic structure determination by neutron powder diffraction. Physica B 192, 55-69.

Rojas, J.M., Gavilan, H., del Dedo, V., Lorente-Sorolla, E., Sanz-Ortega, L., da Silva, G.B., Costo, R., Perez-Yague, S., Talelli, M., Marciello, M., Morales, M.P., Barber, D.F., Gutierrez, L., 2017. Time-course assessment of the aggregation and metabolization of magnetic nanoparticles. Acta Biomater 58, 181-195.

Roohi, F., Lohrke, J., Ide, A., Schutz, G., Dassler, K., 2012. Studying the effect of particle size and coating type on the blood kinetics of superparamagnetic iron oxide nanoparticles. Int J Nanomed 7, 4447-4458.

Sadeghi, L., Tanwir, F., Babadi, V.Y., 2015. In vitro toxicity of iron oxide nanoparticle: Oxidative damages on Hep G2 cells. Exp Toxicol Pathol 67, 197-203.

Said-Sadier, N., Padilla, E., Langsley, G., Ojcius, D.M., 2010. Aspergillus fumigatus Stimulates the NLRP3 Inflammasome through a Pathway Requiring ROS Production and the Syk Tyrosine Kinase. Plos One 5.

Salazar, J.S., Perez, L., de Abril, O., Lai, T.P., Ihiawakrim, D., Vazquez, M., Greneche, J.M., Begin-Colin, S., Pourroy, G., 2011. Magnetic Iron Oxide Nanoparticles in 10-40 nm Range: Composition in Terms of Magnetite/Maghemite Ratio and Effect on the Magnetic Properties. Chem Mater 23, 1379-1386.

Sarkar, S., Leo, B.F., Carranza, C., Chen, S., Rivas-Santiago, C., Porter, A.E., Ryan, M.P., Gow, A., Chung, K.F., Tetley, T.D., Zhang, J.F., Georgopoulos, P.G., Ohman-Strickland, P.A., Schwander, S., 2015. Modulation of Human Macrophage Responses to Mycobacterium tuberculosis by Silver Nanoparticles of Different Size and Surface Modification. Plos One 10. 
Scialla, S., Palazzo, B., Barca, A., Carbone, L., Fiore, A., Monteduro, A.G., Maruccio, G., Sannino, A., Gervaso, F., 2017. Simplified preparation and characterization of magnetic hydroxyapatite-based nanocomposites. Mat Sci Eng C-Mater 76, 1166-1174.

Sharma, G., Kodali, V., Gaffrey, M., Wang, W., Minard, K.R., Karin, N.J., Teeguarden, J.G., Thrall, B.D., 2014. Iron oxide nanoparticle agglomeration influences dose rates and modulates oxidative stress-mediated dose-response profiles in vitro. Nanotoxicology 8 , 663-675.

Simard, J.C., Vallieres, F., de Liz, R., Lavastre, V., Girard, D., 2015. Silver Nanoparticles Induce Degradation of the Endoplasmic Reticulum Stress Sensor Activating Transcription Factor-6 Leading to Activation of the NLRP-3 Inflammasome. J Biol Chem 290, 5926-5939.

Singh, N., Jenkins, G.J.S., Nelson, B.C., Marquis, B.J., Maffeis, T.G.G., Brown, A.P., Williams, P.M., Wright, C.J., Doak, S.H., 2012. The role of iron redox state in the genotoxicity of ultrafine superparamagnetic iron oxide nanoparticles. Biomaterials 33, 163-170.

Soenen, S.J., Parak, W.J., Rejman, J., Manshian, B., 2015. (Intra)Cellular Stability of Inorganic Nanoparticles: Effects on Cytotoxicity, Particle Functionality, and Biomedical Applications. Chem Rev 115, 2109-2135.

Soenen, S.J.H., Himmelreich, U., Nuytten, N., De Cuyper, M., 2011. Cytotoxic effects of iron oxide nanoparticles and implications for safety in cell labelling. Biomaterials 32, 195205.

Soenen, S.J.H., Nuytten, N., De Meyer, S.F., De Smedt, S.C., De Cuyper, M., 2010. High Intracellular Iron Oxide Nanoparticle Concentrations Affect Cellular Cytoskeleton and Focal Adhesion Kinase-Mediated Signaling. Small 6, 832-842.

Sonvico, F., Mornet, S., Vasseur, S., Dubernet, C., Jaillard, D., Degrouard, J., Hoebeke, J., Duguet, E., Colombo, P., Couvreur, P., 2005. Folate-conjugated iron oxide nanoparticles for solid tumor targeting as potential specific magnetic hyperthermia mediators: Synthesis, physicochemical characterization, and in vitro experiments. Bioconjugate Chem 16, 1181-1188.

Sun, C.R., Du, K., Fang, C., Bhattarai, N., Veiseh, O., Kievit, F., Stephen, Z., Lee, D.H., Ellenbogen, R.G., Ratner, B., Zhang, M.Q., 2010. PEG-Mediated Synthesis of Highly Dispersive Multifunctional Superparamagnetic Nanoparticles: Their Physicochemical Properties and Function In Vivo. Acs Nano 4, 2402-2410.

Sutterwala, F.S., Haasken, S., Cassel, S.L., 2014. Mechanism of NLRP3 inflammasome activation. Ann Ny Acad Sci 1319, 82-95.

Thompson, P., Cox, D.E., Hastings, J.B., 1987. Rietveld Refinement of Debye-Scherrer Synchrotron X-Ray Data from Al2o3. J Appl Crystallogr 20, 79-83.

Thorek, D.L.J., Tsourkas, A., 2008. Size, charge and concentration dependent uptake of iron oxide particles by non-phagocytic cells. Biomaterials 29, 3583-3590.

Wagner, M., Wagner, S., Schnorr, J., Schellenberger, E., Kivelitz, D., Krug, L., Dewey, M., Laule, M., Hamm, B., Taupitz, M., 2011. Coronary MR angiography using citrate-coated very small superparamagnetic iron oxide particles as blood-pool contrast agent: initial experience in humans. J Magn Reson Imaging 34, 816-823. 
Walkey, C.D., Olsen, J.B., Guo, H.B., Emili, A., Chan, W.C.W., 2012. Nanoparticle Size and Surface Chemistry Determine Serum Protein Adsorption and Macrophage Uptake. J Am Chem Soc 134, 2139-2147.

Walter, A., Billotey, C., Garofalo, A., Ulhaq-Bouillet, C., Lefevre, C., Taleb, J., Laurent, S., Vander Elst, L., Muller, R.N., Lartigue, L., Gazeau, F., Felder-Flesch, D., Begin-Colin, S., 2014. Mastering the Shape and Composition of Dendronized Iron Oxide Nanoparticles To Tailor Magnetic Resonance Imaging and Hyperthermia. Chem Mater 26, 5252-5264.

Walter, A., Garofalo, A., Parat, A., Jouhannaud, J., Pourroy, G., Voirin, E., Laurent, S., Bonazza, P., Taleb, J., Billotey, C., Elst, L.V., Muller, R.N., Begin-Colin, S., Felder-Flesch, D., 2015. Validation of a dendron concept to tune colloidal stability, MRI relaxivity and bioelimination of functional nanoparticles. J Mater Chem B 3, 1484-1494.

Weissleder, R., Elizondo, G., Wittenberg, J., Lee, A.S., Josephson, L., Brady, T.J., 1990. Ultrasmall Superparamagnetic Iron-Oxide - an Intravenous Contrast Agent for Assessing Lymph-Nodes with Mr Imaging. Radiology 175, 494-498.

Wilhelm, C., Gazeau, F., 2008. Universal cell labelling with anionic magnetic nanoparticles. Biomaterials 29, 3161-3174.

Wu, H.Y., Chung, M.C., Wang, C.C., Huang, C.H., Liang, H.J., Jan, T.R., 2013. Iron oxide nanoparticles suppress the production of IL-1beta via the secretory lysosomal pathway in murine microglial cells. Part Fibre Toxicol 10.

Ying, E.B., Hwang, H.M., 2010. In vitro evaluation of the cytotoxicity of iron oxide nanoparticles with different coatings and different sizes in A3 human T lymphocytes. Sci Total Environ 408, 4475-4481.

Yu, M., Huang, S.H., Yu, K.J., Clyne, A.M., 2012. Dextran and Polymer Polyethylene Glycol (PEG) Coating Reduce Both 5 and $30 \mathrm{~nm}$ Iron Oxide Nanoparticle Cytotoxicity in 2D and 3D Cell Culture. Int J Mol Sci 13, 5554-5570.

Zhang, L., Wang, X.Q., Miao, Y.M., Chen, Z.Q., Qiang, P.F., Cui, L.Q., Jing, H.J., Guo, Y.Q., 2016. Magnetic ferroferric oxide nanoparticles induce vascular endothelial cell dysfunction and inflammation by disturbing autophagy. J Hazard Mater 304, 186-195.

Zhu, X.M., Wang, Y.X.J., Leung, K.C.F., Lee, S.F., Zhao, F., Wang, D.W., Lai, J.M.Y., Wan, C., Cheng, C.H.K., Ahuja, A.T., 2012. Enhanced cellular uptake of aminosilane-coated superparamagnetic iron oxide nanoparticles in mammalian cell lines. Int J Nanomed 7, 953-964. 
Fig. 1. Scheme of the three phosphonated molecules grafted onto the IONPs NP10COP: linear (2P), dendritic and of generation 1 (2PG1) and dendritic and of generation 2 (2PG2)

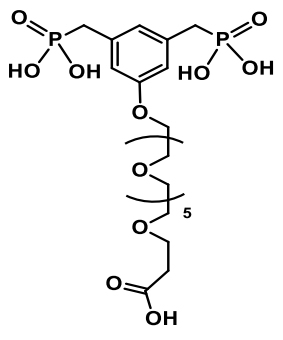

$2 \mathrm{P}$

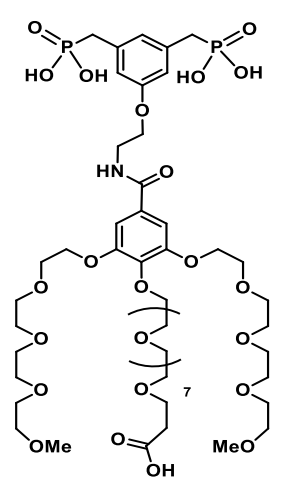

2PG1

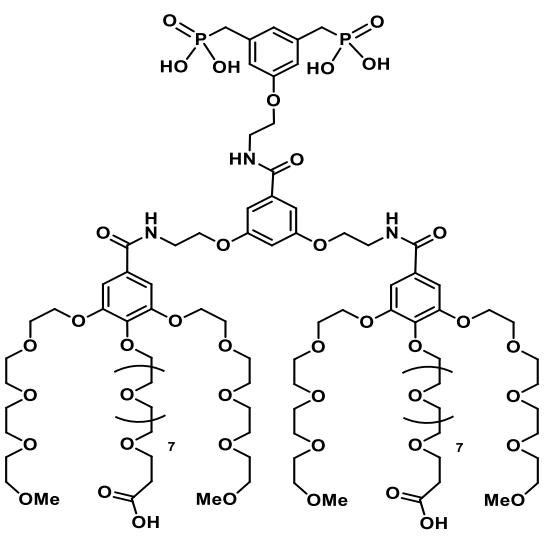

2PG2 
Fig. 2. TEM images of bare NP10COP in water suspension (A, B) together with particle size distribution determined by the ImageJ software (C).
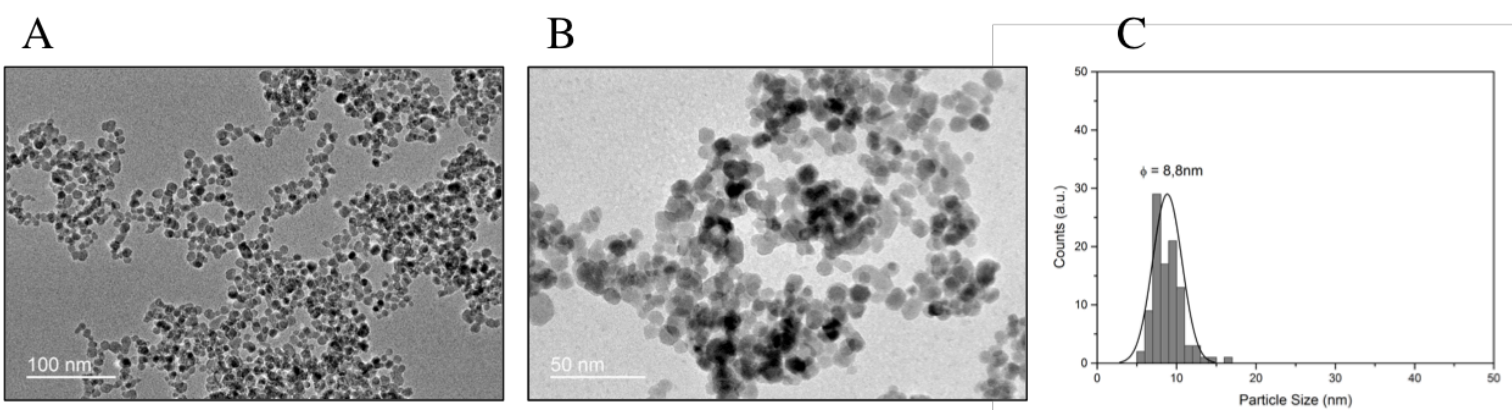
Fig. 3. Dose-dependent cytotoxic effects of IONPs, as assessed by mitochondrial function (A) and membrane integrity (B) measurements. THP-1-derived macrophages were exposed to increasing concentrations $(0-300 \mu \mathrm{g} \quad \mathrm{Fe} / \mathrm{mL})$ of NP10COP@2P (white bars), NP10COP@2PG1 (grey bars) or NP10COP@2PG2 (black bars) for 24h. At the end of the exposure, cell mitochondrial activity and membrane integrity were assessed by MTT (A) and LDH (B) assays, respectively. Data presented are mean values \pm SEM of 4 independent experiments. Significance compared to untreated cells as negative control. ${ }^{*} \mathrm{p} \leq 0.05$ and $* * \mathrm{p}$ $\leq 0.01 * * * \mathrm{p} \leq 0.001$ versus respective controls.
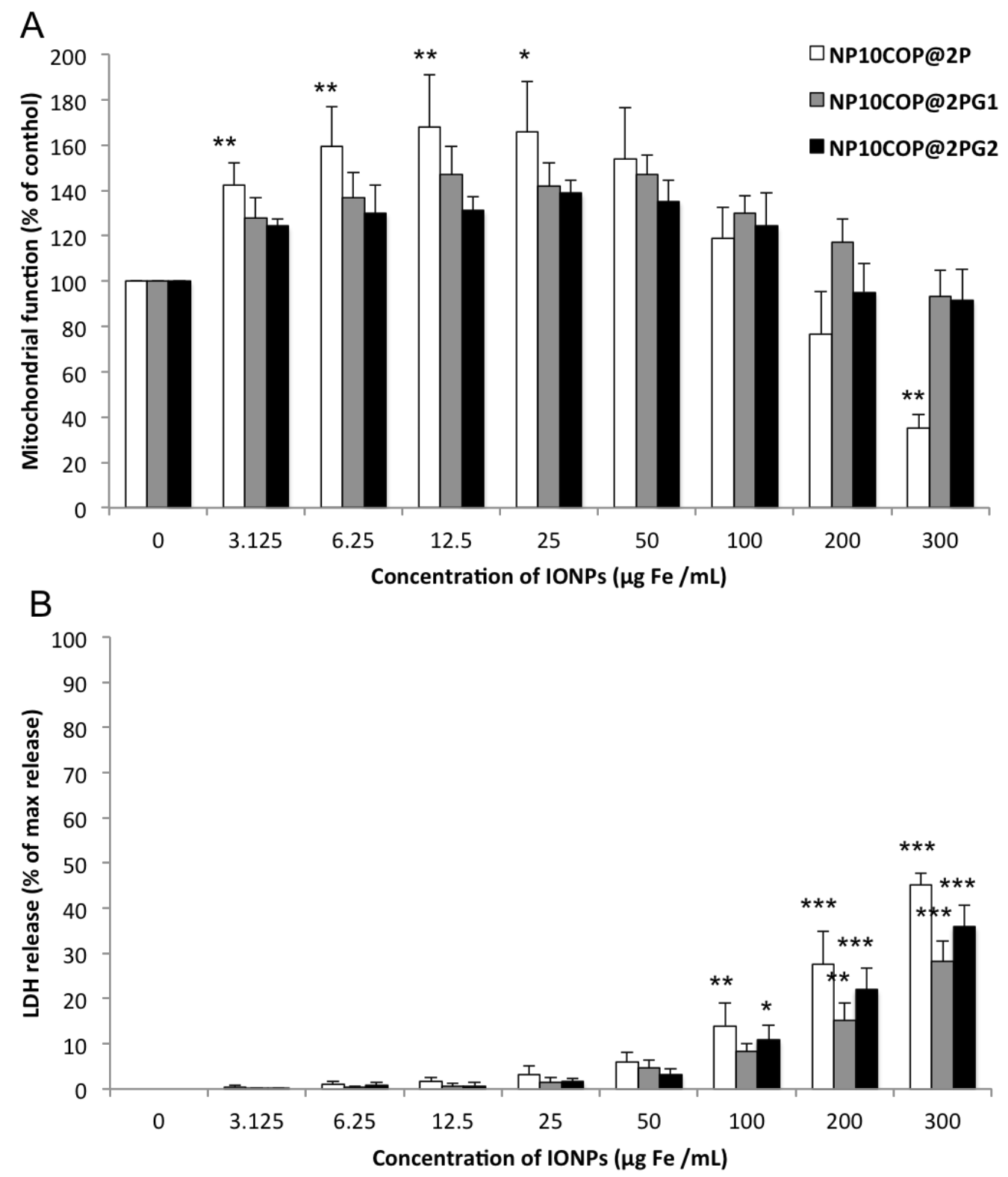
Fig. 4. Effects of a post-exposure recovery period on cytotoxicity and inflammation. THP-1derived macrophages were exposed to increasing concentrations $(0-300 \mu \mathrm{g} \mathrm{Fe} / \mathrm{mL})$ of NP10COP@2P (white bars), NP10COP@2PG1 (grey bars) or NP10COP@2PG2 (black bars) for $4 \mathrm{~h}$. Cytotoxicity was measured by MTT and LDH assays at the end of the 4-h exposure ( $\mathrm{A}=\mathrm{MTT}$ and $\mathrm{B}=\mathrm{LDH})$ or and the end of a 20 -h recovery period $(\mathrm{C}=\mathrm{MTT}$ and $\mathrm{D}=\mathrm{LDH})$. $(\mathrm{E}$ and F) Inflammation was assessed at the end of the recovery period by measuring IL-8 (E) and IL-6 (F) levels in cell culture supernatants. Data presented are mean values \pm SEM of 6 independent experiments, excepted for the MTT data at $4 \mathrm{~h}(\mathrm{n}=3$ independent conditions). Significance compared to untreated cells as negative control. ${ }^{*} \mathrm{p} \leq 0.05$ and $* * \mathrm{p} \leq 0.01 * * * \mathrm{p}$ $\leq 0.001$ versus respective controls.
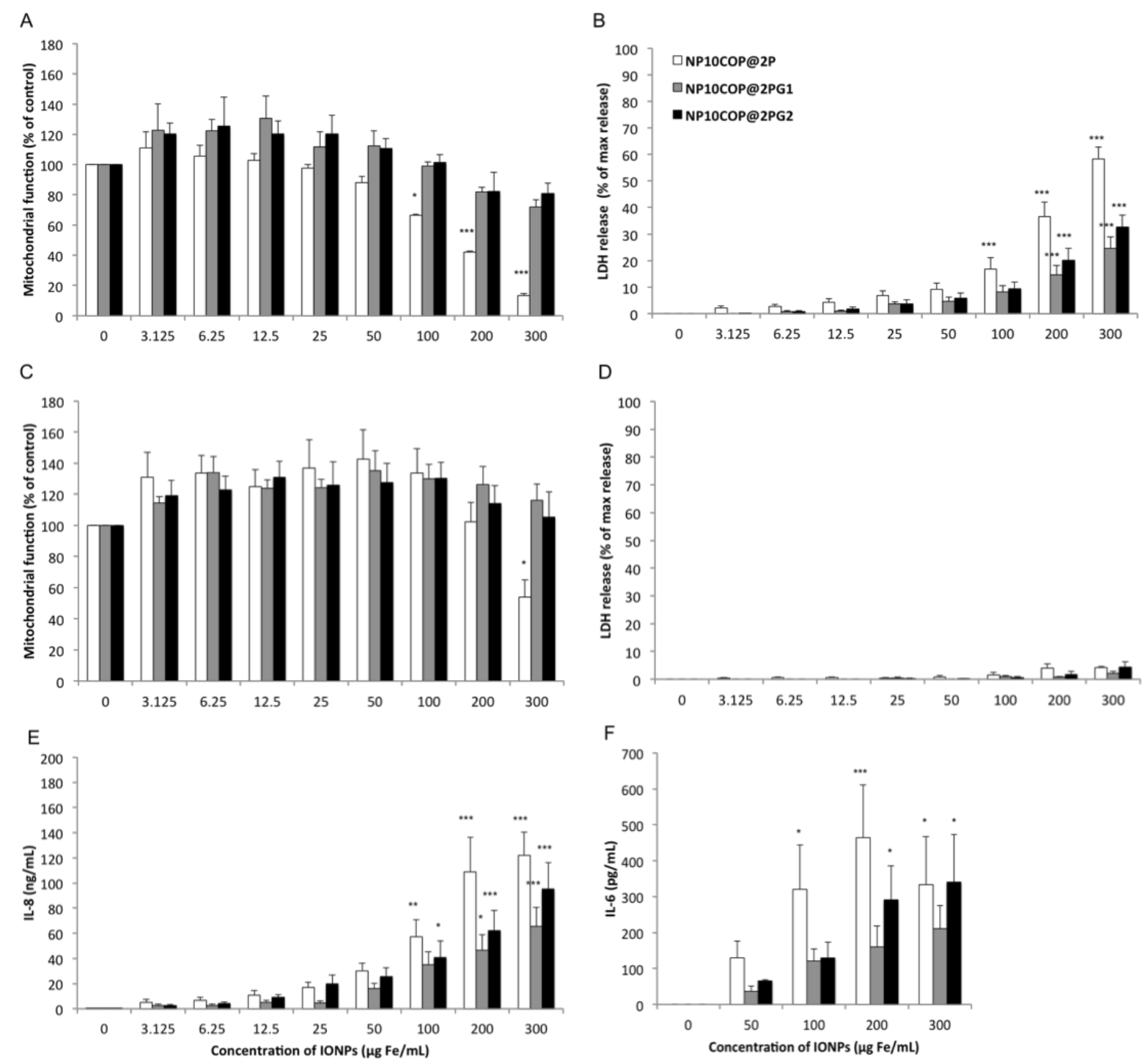
Fig. 5. Effects of IONPs on intracellular reduced glutathione (GSH) levels. PMA-activated THP-1 cells were exposed to increasing concentrations (0-300 $\mu \mathrm{g} \mathrm{Fe} / \mathrm{mL})$ of NP10COP@2P (white bars), NP10COP@2PG1 (grey bars) or NP10COP@2PG2 (black bars) or to $\mathrm{H}_{2} \mathrm{O}_{2}(100$ $\mathrm{mM}$ ) as positive control for $4 \mathrm{~h}$. The intracellular GSH levels were determined using the naphthalene-2,3-dicarboxaldehyde probe. Data presented are mean values \pm SEM of 3 independent experiments. Significance compared to untreated cells as negative control. $* \mathrm{p} \leq$ 0.05 and $* * \mathrm{p} \leq 0.01 * * * \mathrm{p} \leq 0.001$ versus the respective controls.

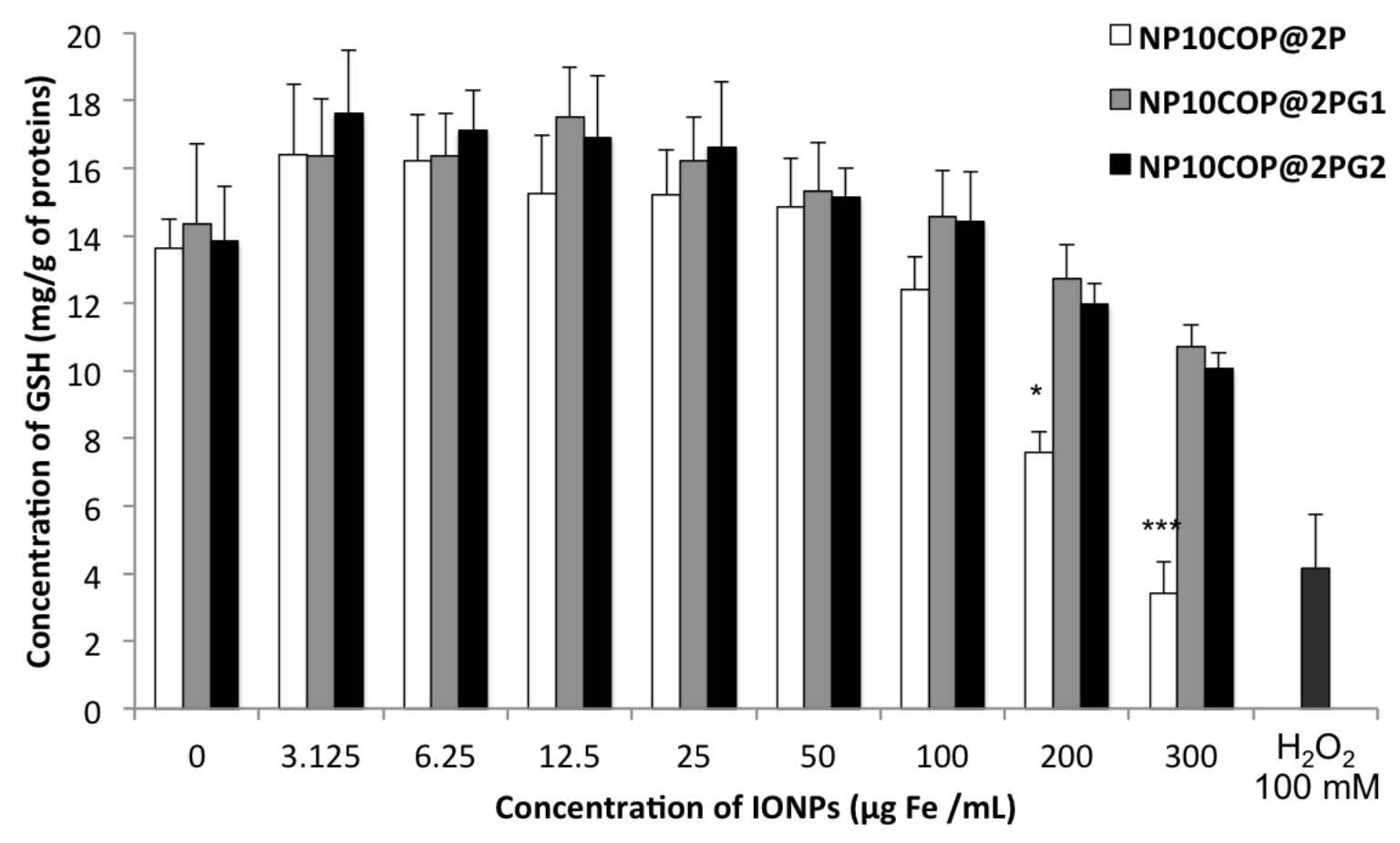


Fig. 6. Effects of IONPs on NLRP3 inflammasome. PMA-activated THP-1 cells were exposed to increasing concentrations $(0-300 \mu \mathrm{g} \mathrm{Fe} / \mathrm{mL})$ of NP10COP@2P (white bars), NP10COP@2PG1 (grey bars) or NP10COP@2PG2 (black bars) or to $0.1 \mu \mathrm{g} \mathrm{mL}$ - LPS for 4 $\mathrm{h}$. Concentrations of IL- $1 \beta$ were measured in cell culture supernatants by ELISA at the end of the exposure period. Data presented are mean values \pm SEM of 4 independent experiments. Significance compared to untreated cells as negative control. $* \mathrm{p} \leq 0.05$ and $* * \mathrm{p} \leq 0.01 * * * \mathrm{p}$ $\leq 0.001$ versus respective controls.

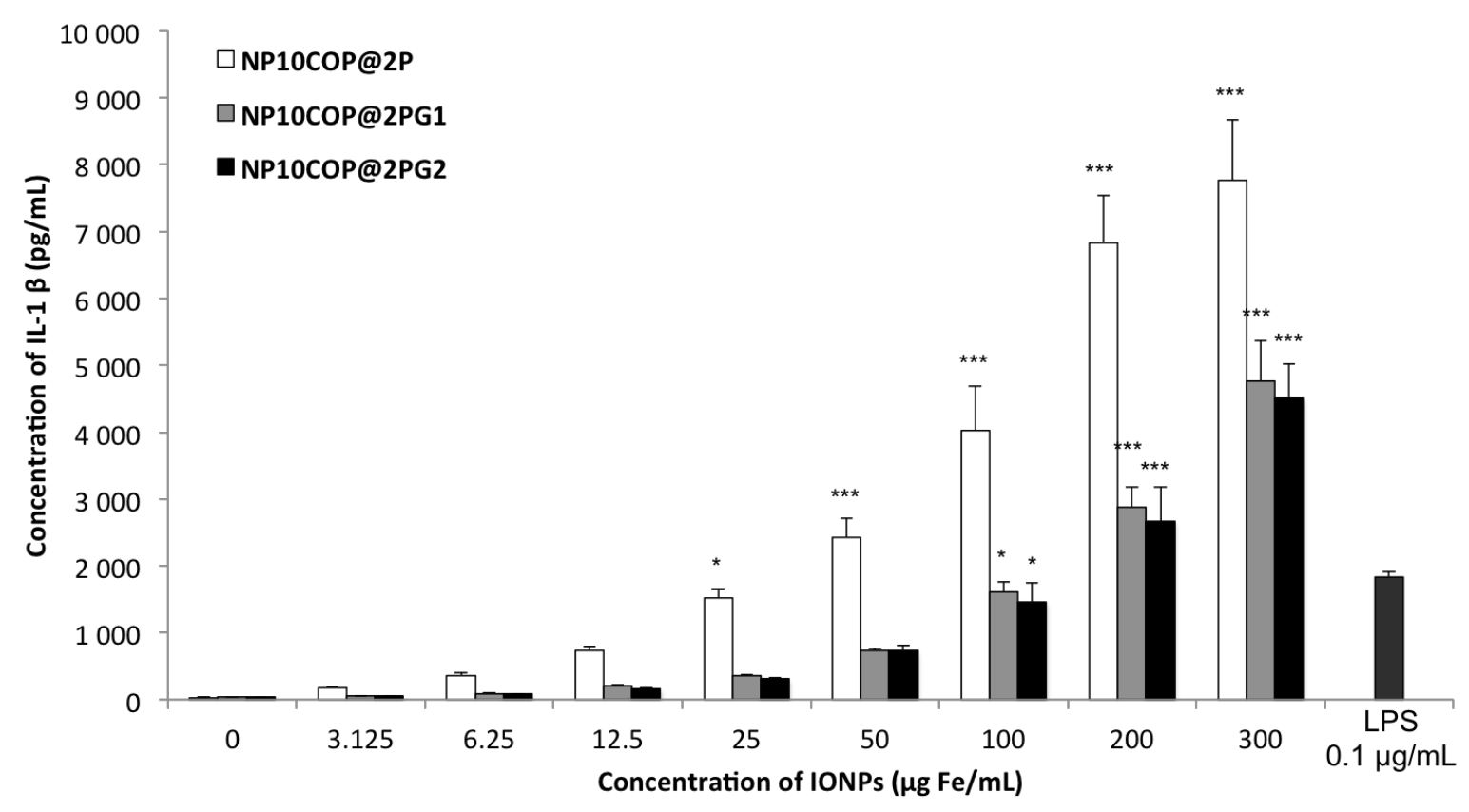


Fig. 7. Intracellular iron quantification in cells exposed to IONPs. PMA-activated THP-1 cells were exposed to NP10COP@2P, NP10COP@2PG1 or NP10COP@2PG2 (100 $\mu \mathrm{g} \mathrm{Fe} / \mathrm{mL})$ for $4 \mathrm{~h}$. At the end of exposure, iron content was determined by a colorimetric method using a standard curve. The iron concentration of each sample was reported to the number of cells in order to determine the average iron concentration per cell. Data presented are mean values \pm SEM of 4 independent experiments. Statistical significance was determined by one-way ANOVA followed by Tukey's multiple comparisons test. **p $\leq 0.01$ and ***p $\leq 0.001$ versus the untreated cells.

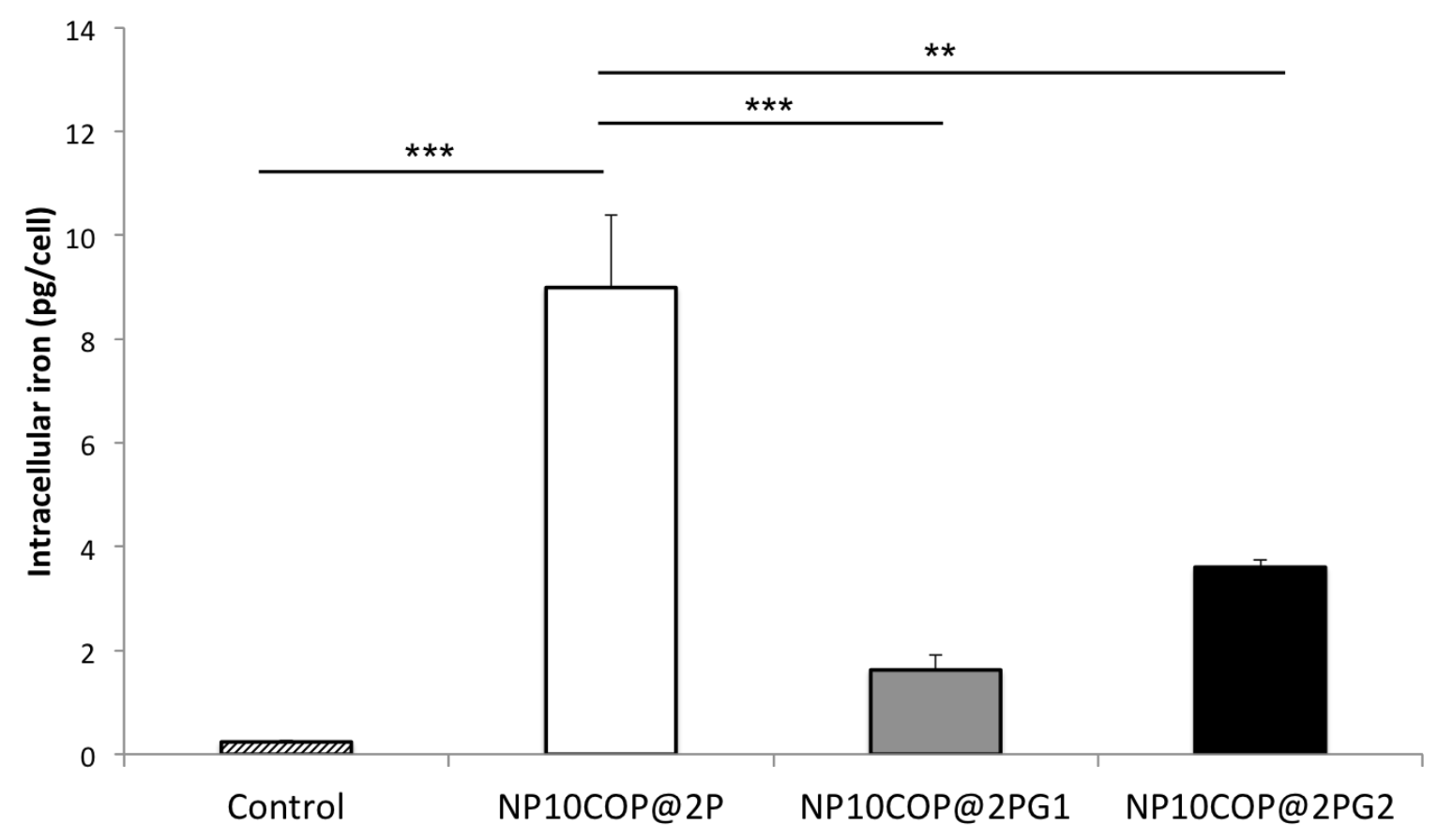


Fig. 8. TEM images of cells exposed to the IONPs. PMA-activated THP-1 cells were exposed to NP10COP@2P, NP10COP@2PG1 or NP10COP@2PG2 (100 $\mu \mathrm{g} \mathrm{Fe} / \mathrm{mL})$ for 4 h. (A) Low magnification (bar $5 \mu \mathrm{m})$; (B, C) High magnification (bar=200 nm) ; (D, E) Very high magnification on samples without uranyl acetate and lead acetate post-staining (bar $=500 \mathrm{~nm}$ and $100 \mathrm{~nm}$, respectively). Arrows indicate IONPs.

\section{NP10COP@2P}

A

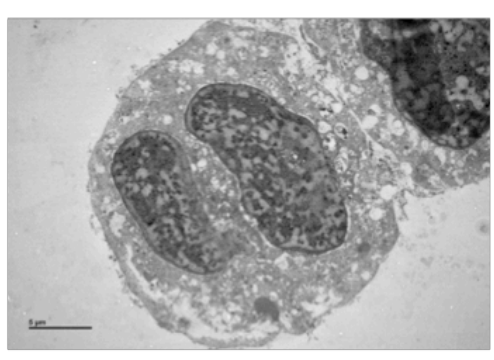

B

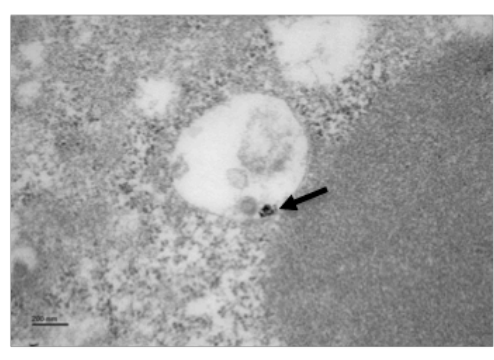

C

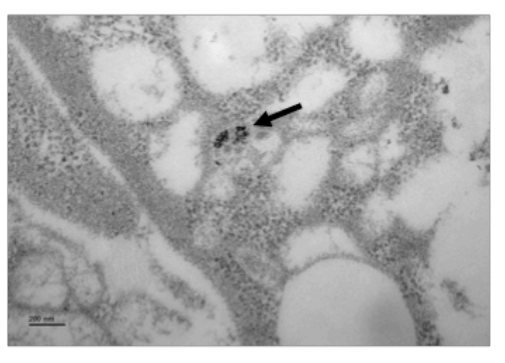

D

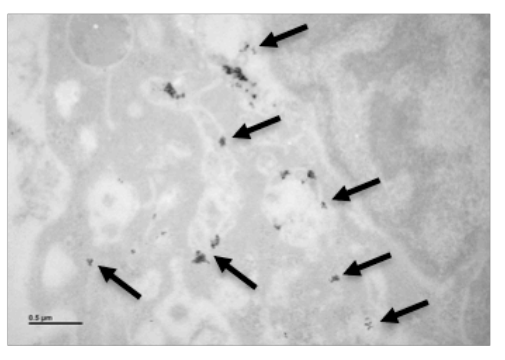

E

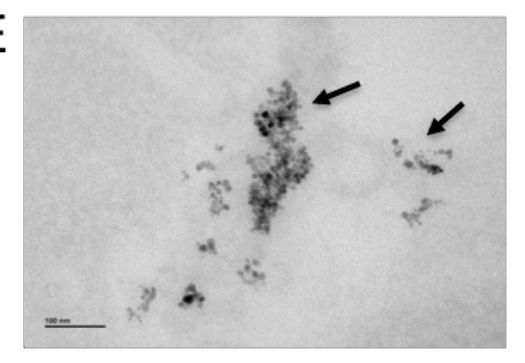

NP10COP@2PG1
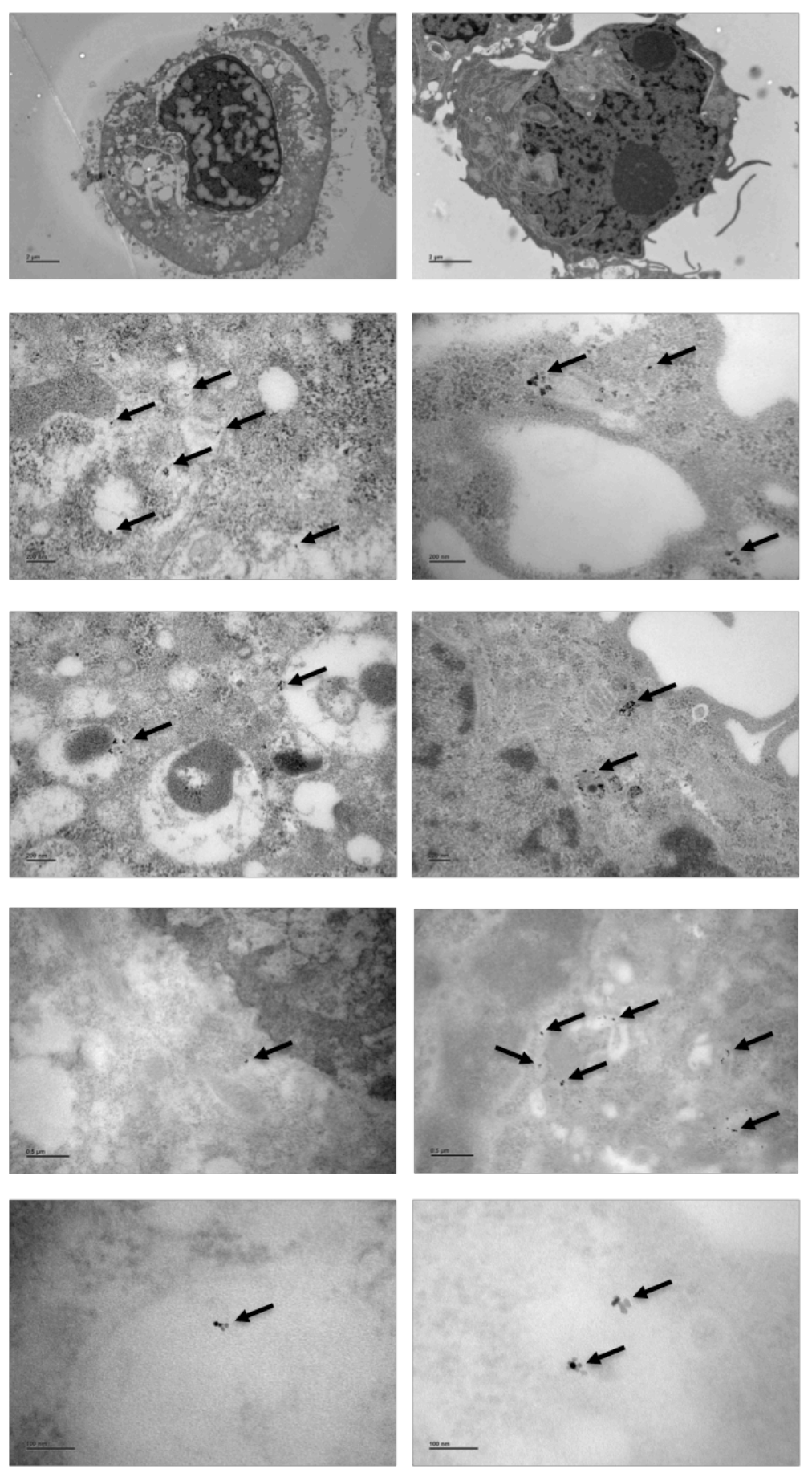
Fig. 9. IONP surface coating effects on cytotoxicity and inflammation. PMA-activated THP-1 cells were exposed to increasing concentrations (0-200 $\mu \mathrm{g} \mathrm{Fe} / \mathrm{mL}$ ) of NP10COP@2PG1 (grey bars) or NP10COP@2PG2 (black bars) for $30 \mathrm{~min}$ or 1h30, followed or not by a recovery period in NPs-free culture medium up to $24 \mathrm{~h}$. At the endpoints $30 \mathrm{~min}$ and $1 \mathrm{~h} 30$, membrane integrity (A) and inflammasome activation (B) were measured by assaying LDH release and IL-1 $\beta$ secretion, respectively. (C) At the end of the recovery period, IL- 8 was measured by ELISA. Data presented are mean values \pm SEM of 2 to 4 independent experiments. Statistical significance was determined by two-way ANOVA followed by Bonferroni's multiple comparisons test. $* \mathrm{p} \leq 0.05$ and $* * \mathrm{p} \leq 0.01 * * * \mathrm{p} \leq 0.001$ versus NP10COP@2PG2 group.
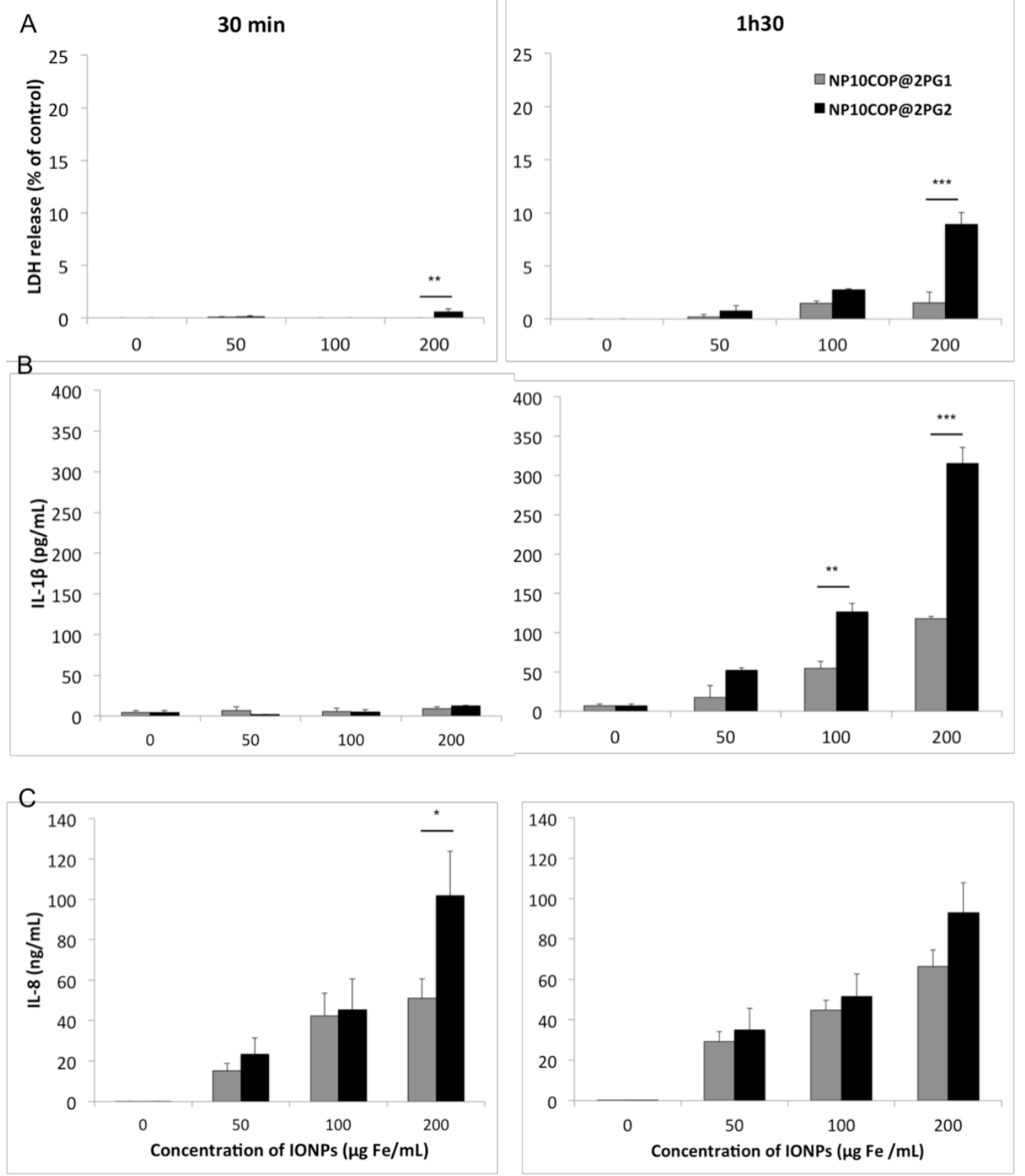


\section{Table 1}

Zeta Potential (ZP) and average size of the IONPs analyzed by Dynamic Light Scattering (DLS).

\begin{tabular}{|l|l|l|l|}
\hline Sample & $\mathrm{pH}$ & $\begin{array}{l}\text { Average size } \\
(\mathrm{nm})\end{array}$ & $\begin{array}{l}\text { Zeta potential } \\
(\mathrm{mV})\end{array}$ \\
\hline NP10COP & 4.0 & $95 \pm 5$ & $39 \pm 2$ \\
\hline NP10COP@2P & 7.4 & $140 \pm 10$ & $-24 \pm 2$ \\
\hline NP10COP@2PG1 & 7.4 & $72 \pm 5$ & $-30 \pm 2$ \\
\hline NP10COP@2PG2 & 7.4 & $74 \pm 5$ & $-20 \pm 2$ \\
\hline
\end{tabular}

\section{Table 2}

Concentration of iron and phosphorus measured by ICP-AES, molecule concentration, iron to molecule weight ratio and grafting ratios expressed in molecule $/ \mathrm{nm}^{2}$ assuming that NP10COP NPs are spherical with a diameter of $8.8 \mathrm{~nm}$.

\begin{tabular}{|l|l|l|l|}
\hline & NP10COP@2P & NP10COP@2PG1 & NP10COP2PG2 \\
\hline Molecular weight (g) & 618.18 & 1285.50 & 2461.55 \\
\hline Fe (mg/ml) & $0.957 \pm 0.042$ & $2.208 \pm 0.097$ & $1.772 \pm 0.078$ \\
\hline $\mathrm{P} \mathrm{(mg/ml)}$ & $7.4 \times 10^{3} \pm 0.5 \times 10^{3}$ & $15.4 \times 10^{3} \pm 0.6 \times 10^{3}$ & $8.7 \times 10^{3} \pm 0.2 \times 10^{3}$ \\
\hline Molecule (mg/ml) & $0.074 \pm 0.05$ & $0.319 \pm 0.013$ & $0.345 \pm 0.008$ \\
\hline $\begin{array}{l}\text { Iron to molecule } \\
\text { weight ratio }\end{array}$ & $13.0 \pm 1.4$ & $6.9 \pm 0.6$ & $5.13 \pm 0.34$ \\
\hline $\begin{array}{l}\text { Molecule to iron } \\
\text { weight ratio }\end{array}$ & $0.077 \pm 0.080$ & $0.14 \pm 0.01$ & $0.195 \pm 0.006$ \\
\hline Molecule/nm ${ }^{2}$ & $0.48 \pm 0.1$ & $0.42 \pm 0.1$ & $0.30 \pm 0.1$ \\
\hline
\end{tabular}




\section{Supplementary information}

\section{X-ray diffraction analysis}

Fig. S1. X-ray diffraction pattern of NP10COP: experimental (dotted line) and calculated (red line) patterns, difference between the experimental and calculated patterns (--black line) and hkl diffraction peaks corresponding to the spinel structure.

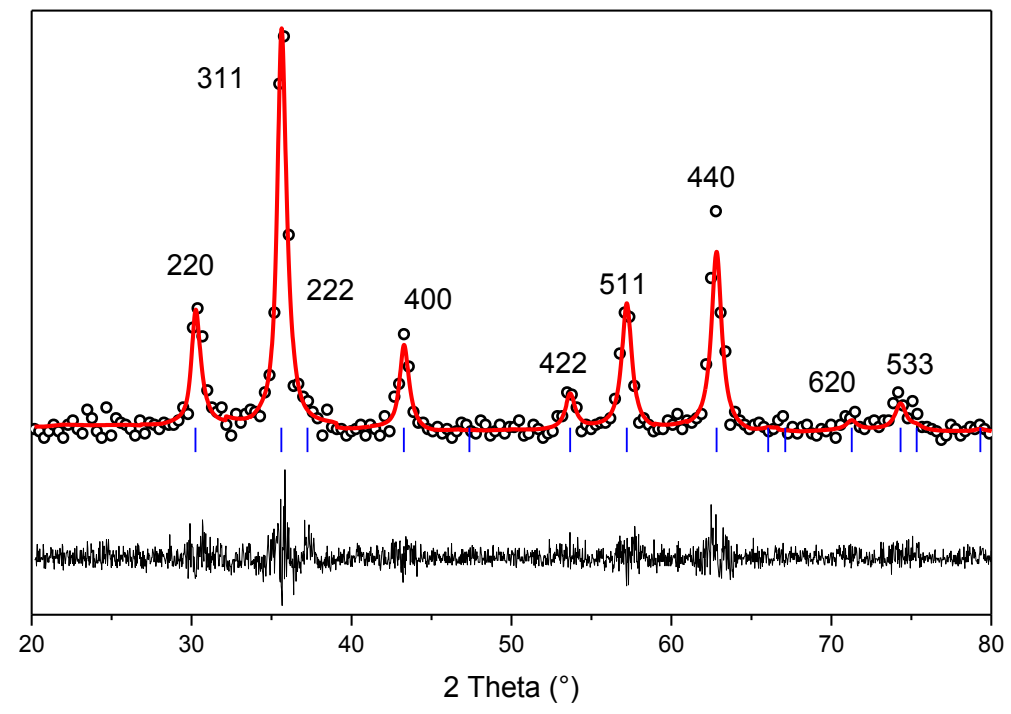




\section{Infrared spectra}

Fig. S2. IR spectra of the three molecules (A): linear (2P), dendritic and of generation 1 (2PG1) and dendritic and of generation 2 (2PG2). IR spectra of NP10COP, NP10COP@2P, NP10COP@2PG1 and NP10COP@2PG2 suspensions (B): the wide band at 1300-1700 cm-1 contains the $\mathrm{H}-\mathrm{O}-\mathrm{H}$ bending band. The wide band at $500-800 \mathrm{~cm}^{-1}$ corresponds to $\mathrm{Fe}-\mathrm{O}$ bands of IONP particles.

A

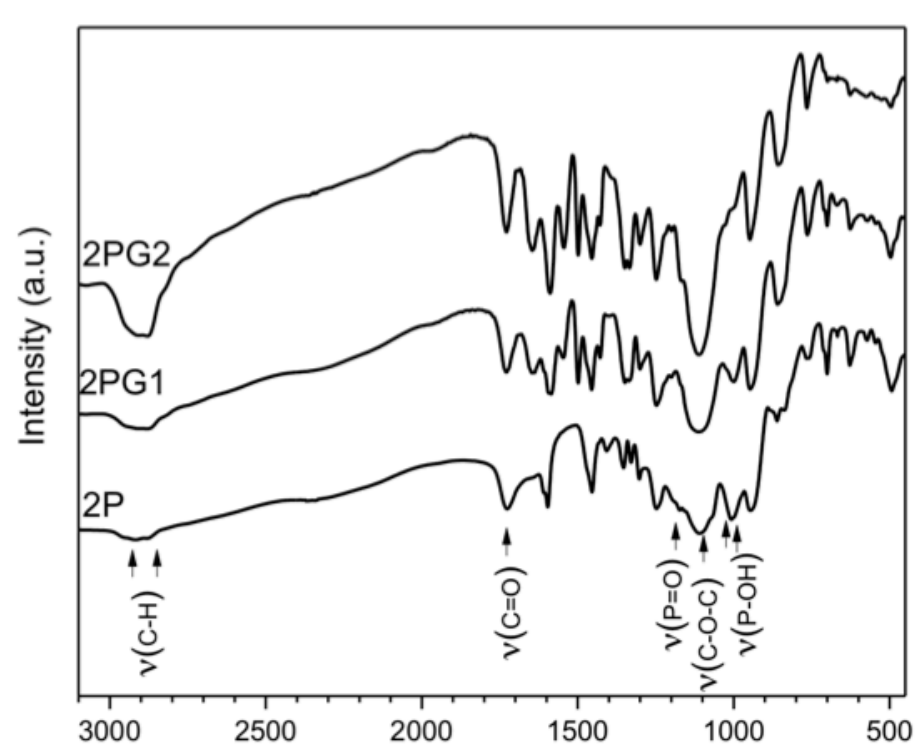

B

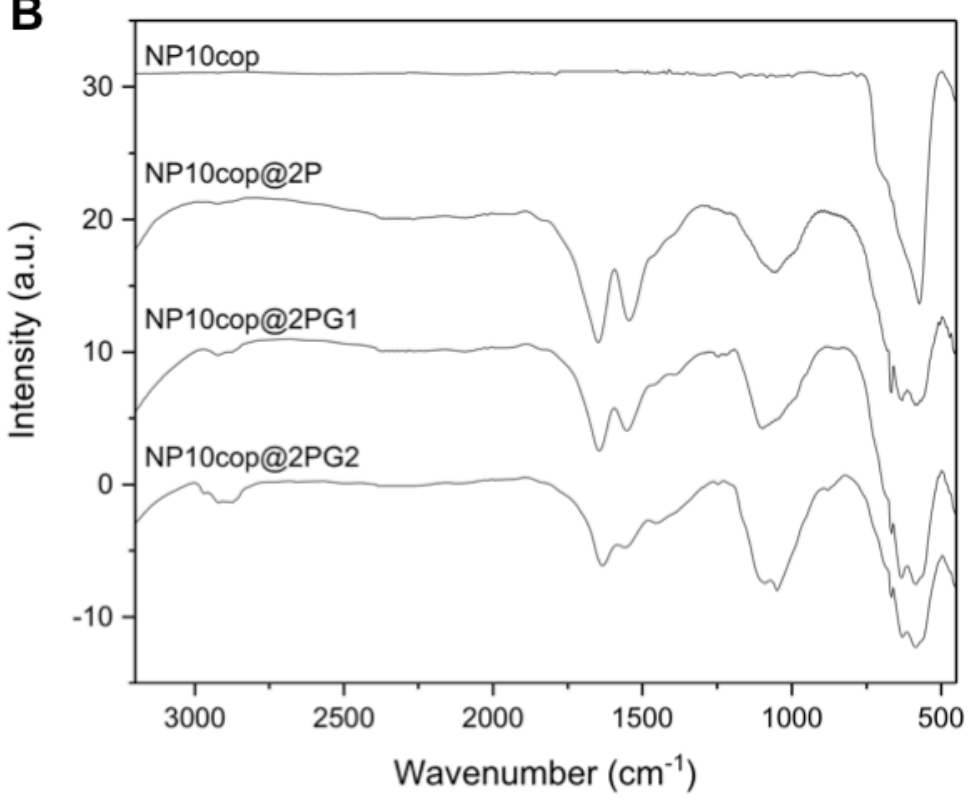




\section{Size aggregates in solution measured by dynamic magnetic measurement}

The dynamic magnetic measurement (i.e., dynamic magnetic susceptibility versus the frequency) was carried out using the DynoMag system (Imego, Sweden) in a frequency range of $10 \mathrm{~Hz}$ up to $100 \mathrm{kHz}$ at a field amplitude of $0.4 \mathrm{kA} / \mathrm{m}$. The dynamic susceptibility is given as the volume susceptibility in $1 \times 10^{-4}-1 \times 10^{-3}$ SI units and is composed by the real $\left(\chi^{\prime}\right)$ and imaginary $(\chi$ ") components of the susceptibility. Two types of relaxation can be observed, the Brownian relaxation accounting for the rotational motion of the aggregates in the solution, and the Neel relaxation accounting for the particle magnetic moment relaxation. Thus, the curves are related to the resonance of either the aggregates or the magnetic moment within the nanoparticle (Botez et al., 2012). The Neel relaxation of nanoparticles occurs above $10^{\circ} \mathrm{Hz}$ and the Brownian relaxation in the $10-10^{\circ} \mathrm{Hz}$ range.

The hydrodynamic diameters distribution was determined by fitting the complex susceptibility $\left(\chi^{\prime \prime}\right)$ data to a model that assumes Brownian relaxation of the aggregates. The hydrodynamic diameter was calculated from the Brownian relaxation time $\tau \mathrm{B}$ using the equation:

$$
d_{H}=\sqrt[3]{\frac{2 k_{B} T \tau_{B}}{\pi \eta_{o}}}
$$

where $k_{B}$ is the Boltzmann constant, $T$ is the absolute temperature, $\eta_{o}$ is the viscosity. The real part decreases when the frequency increases (Fig. S3). The imaginary part exhibits a maximum corresponding to the Brownian motion of the aggregates. The resonance frequency of NP10COP@2P is lower than that of NP10COP@2PG1 and NP10COP@2PG2, showing that the aggregates are bigger in the former than in the latter (Fig. S3). The fitting of the curves lead to sizes in the range 120-150 nm for NP10COP@2P and 65-75 nm for NP10COP@2PG1 and NP10COP@2PG2.

Fig. S3. Real part $\chi$ ' (continuous line) and imaginary part $\chi$ " (dotted line) of the dynamic susceptibility recorded on NP10COP@2P, NP10COP@2PG1 or NP10COP@2PG2 suspensions. 


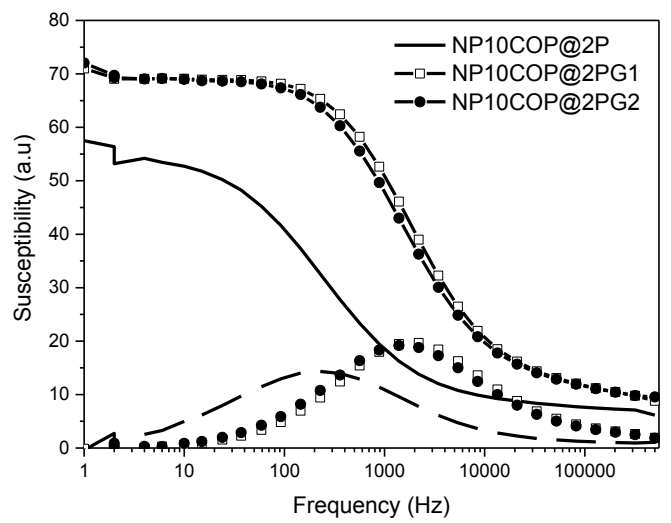




\section{Relaxometry}

Relaxivity of the suspensions was measured at $37^{\circ} \mathrm{C}$ by a NMR spectrometer (Minispec, mq60, Brucker, Germany). The probe was suspended in water at the iron concentrations between 0.01 and $10 \mathrm{mM}$. For MR measurements, $0.25 \mathrm{~mL}$ suspensions dilutions were filled into each of the test tubes, and $T_{1}$ and $T_{2}$ relaxation times were measured using a standard Carr-Purcell-Meiboom-Gill pulse sequence. The measurement at each iron concentration was done in triplicate and the average $T_{1}$ and $T_{2}$ time were taken. The $T_{1}$ and $T_{2}$ relaxivity were determined by a linear fit of the inverse relaxation times as a function of the iron concentrations.

\section{Table S1}

\begin{tabular}{|l|l|l|l|l|l|}
\hline & $\begin{array}{l}\mathbf{C}_{\mathrm{Fe}} \\
\left(\mathbf{m g , m l} \mathbf{- 1}^{-1}\right)\end{array}$ & $\begin{array}{l}\mathbf{C}_{\mathrm{Fe}} \\
(\mathbf{m M})\end{array}$ & $\begin{array}{l}\mathbf{r}_{\mathbf{1}} \\
\left(\mathbf{m M}^{-1} \mathbf{s}^{-\mathbf{1}}\right)\end{array}$ & $\begin{array}{l}\mathbf{r}_{\mathbf{2}} \\
\left(\mathbf{m M}^{-1} \mathbf{s}^{-1}\right)\end{array}$ & $\mathbf{r}_{2} / \mathbf{r}_{\mathbf{1}}$ \\
\hline NP10COP@2P & 0.21 & 3.7604 & 14.9 & 263.1 & 15.2 \\
\hline NP10COP@2PG1 & 0.21 & 3.7604 & 13.3 & 259.0 & 16.2 \\
\hline NP10COP@2PG2 & 0.20 & 3.5813 & 12.1 & 249.8 & 16.3 \\
\hline
\end{tabular}

Fig. S4.

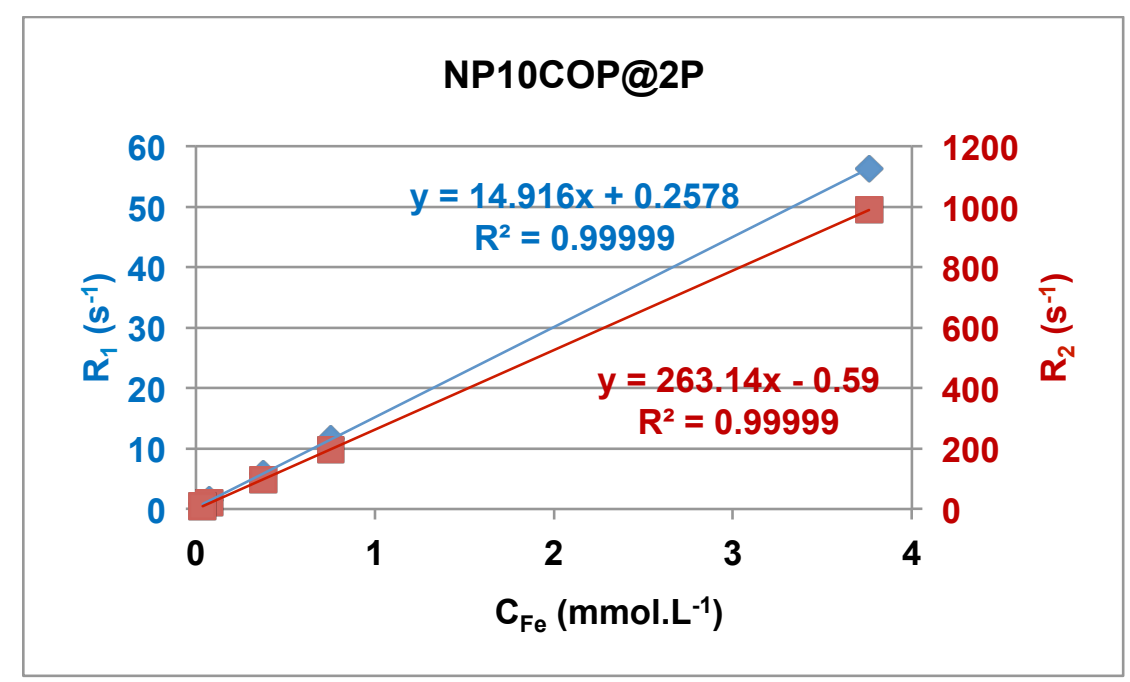




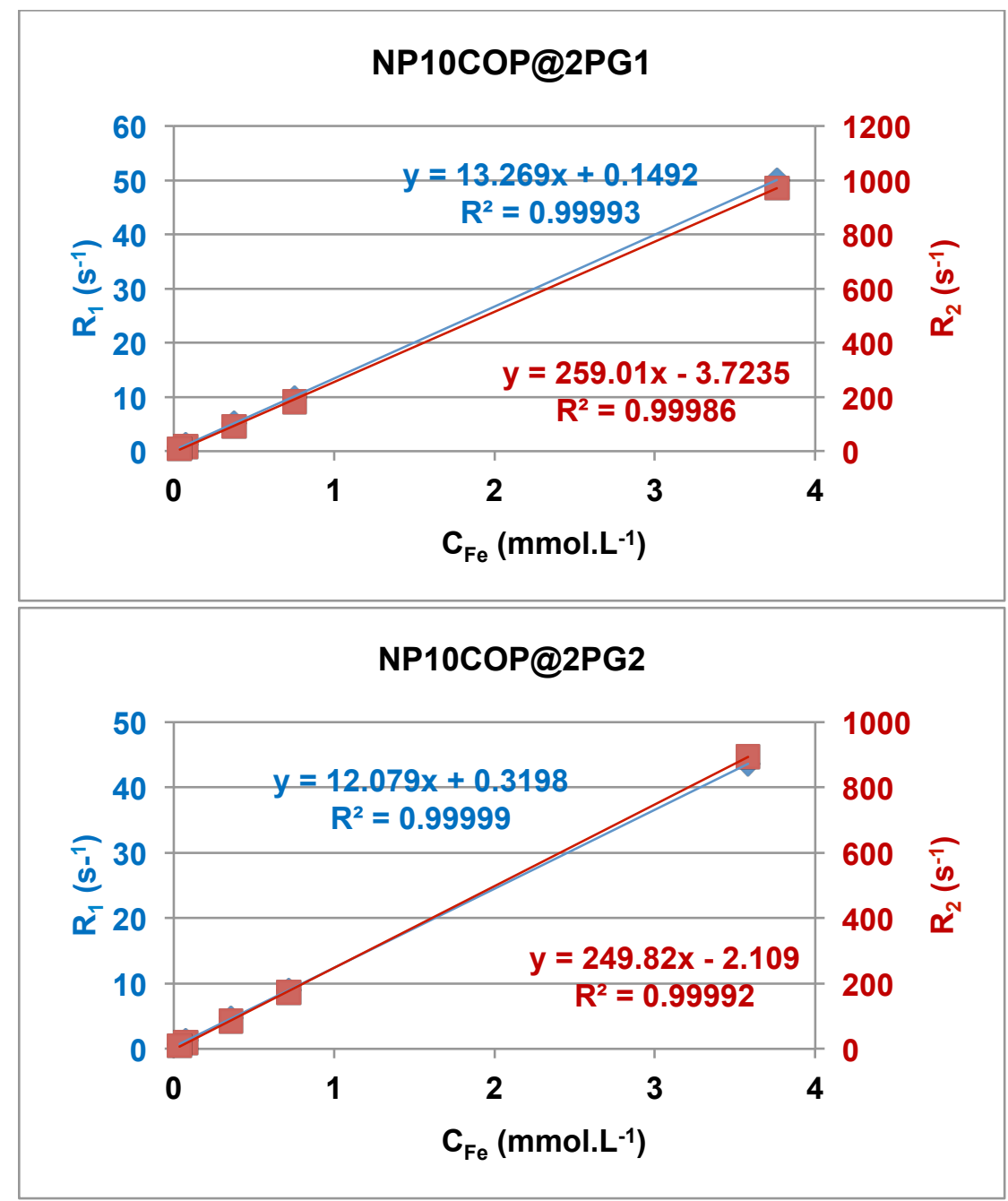

\section{References}

Botez, C. E., Moris, J. L., Eastman M. P., 2012. Superspin relaxation in $\mathrm{Fe}_{3} \mathrm{O}_{4} /$ hexane magnetic fluids: A dynamic susceptibility study. Chemical Physics 403, 89-93. 
6. Cytotoxicity assessment of the three phosphonated molecules before grafting onto NP10COP. THP-1-derived macrophages were exposed to increasing concentrations (C1 to $\mathrm{C} 8$ ) of $2 \mathrm{P}(0.24$ to $23.20 \mu \mathrm{g} / \mathrm{mL}$, white bars $), 2 \mathrm{PG} 1$ (0.45 to $43.34 \mu \mathrm{g} / \mathrm{mL}$, grey bars) or 2PG2 molecule ( 0.60 to $58.41 \mu \mathrm{g} / \mathrm{mL}$, black bars) for $24 \mathrm{~h}$. Coating material concentrations to be tested were determined from each tested concentration of the IONPs $(3.125$ to $300 \mu \mathrm{g} \mathrm{Fe} / \mathrm{mL})$ taking into account the molecule to iron weight ratio (Table 2). Cytotoxicity was measured by MTT assay at the end of the 24-h exposure. Data presented are mean values \pm SEM of 3 independent experiments.

Fig. S5.

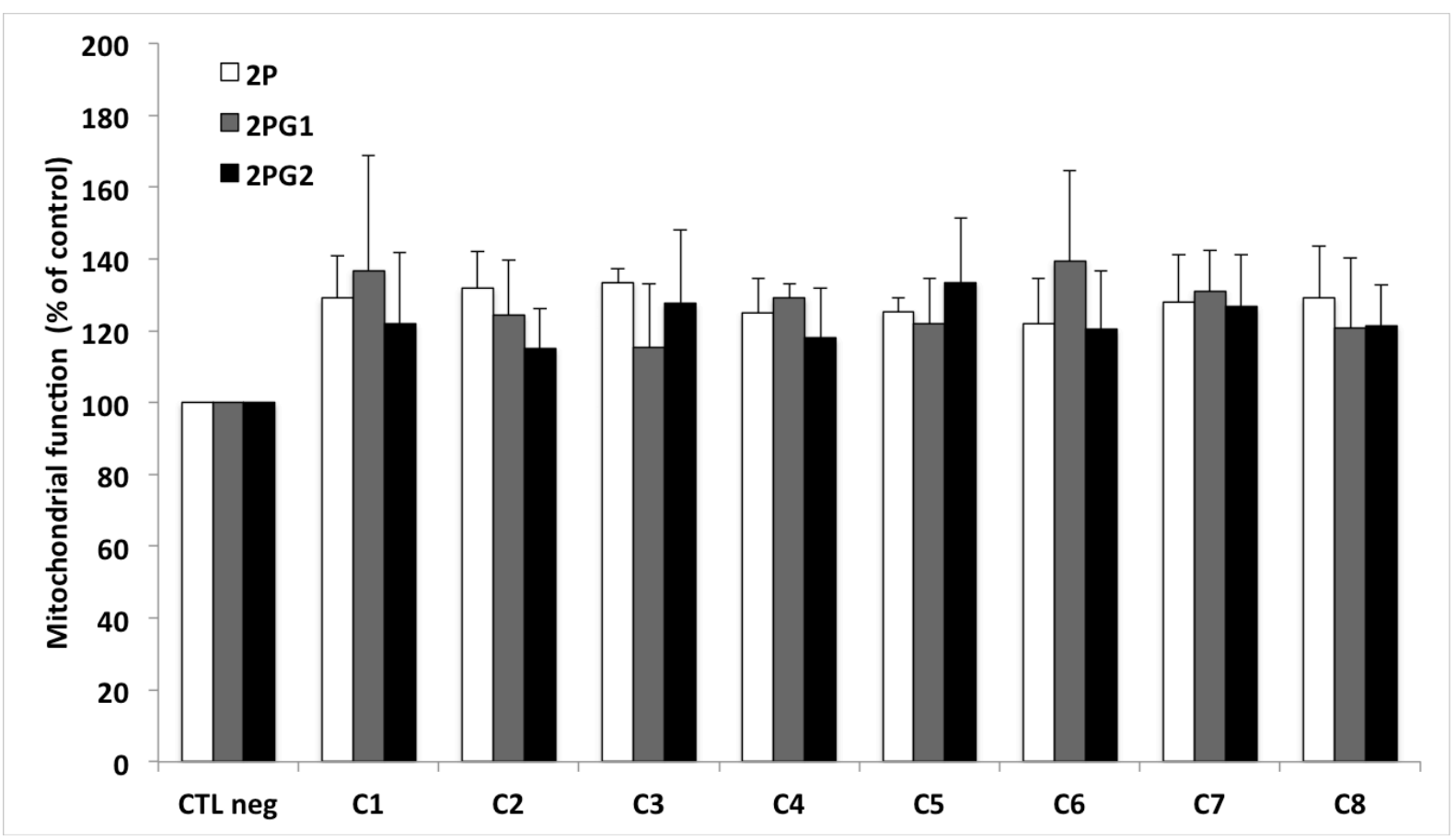

